\title{
Bollène-2002 experiment: radar quantitative precipitation estimation in the Cévennes-Vivarais region, France
}

Article

Published Version

Delrieu, G., Boudevillain, B., Nicol, J., Chapon, B., Kirstetter, P.-E., Andrieu, H. and Faure, D. (2009) Bollène-2002

experiment: radar quantitative precipitation estimation in the Cévennes-Vivarais region, France. Journal of Applied Meteorology and Climatology, 48 (7). pp. 1422-1447. ISSN 1558-8424 doi: https://doi.org/10.1175/2008JAMC1987.1 Available at https://centaur.reading.ac.uk/36318/

It is advisable to refer to the publisher's version if you intend to cite from the work. See Guidance on citing.

To link to this article DOI: http://dx.doi.org/10.1175/2008JAMC1987.1

Publisher: American Meteorological Society

All outputs in CentAUR are protected by Intellectual Property Rights law, including copyright law. Copyright and IPR is retained by the creators or other copyright holders. Terms and conditions for use of this material are defined in the End User Agreement. 


\section{CentAUR}

Central Archive at the University of Reading

Reading's research outputs online 


\title{
Bollène-2002 Experiment: Radar Quantitative Precipitation Estimation in the Cévennes-Vivarais Region, France
}

\author{
Guy Delrieu, Brice Boudevillain, John Nicol,* Benoît Chapon, And \\ PIERRE-EMMANUEL KIRSTETTER \\ Laboratoire d'Étude des Transferts en Hydrologie et Environnement, Grenoble, France \\ HERVÉ ANDRIEU \\ Laboratoire Central des Ponts et Chaussées, Division Eau, Bouguenais, France \\ D. FAURE
}

ALICIME, Messimy sur Saône, France

(Manuscript received 13 March 2008, in final form 9 December 2008)

\begin{abstract}
The Bollène-2002 Experiment was aimed at developing the use of a radar volume-scanning strategy for conducting radar rainfall estimations in the mountainous regions of France. A developmental radar processing system, called Traitements Régionalisés et Adaptatifs de Données Radar pour l'Hydrologie (Regionalized and Adaptive Radar Data Processing for Hydrological Applications), has been built and several algorithms were specifically produced as part of this project. These algorithms include 1) a clutter identification technique based on the pulse-to-pulse variability of reflectivity $Z$ for noncoherent radar, 2) a coupled procedure for determining a rain partition between convective and widespread rainfall $R$ and the associated normalized vertical profiles of reflectivity, and 3) a method for calculating reflectivity at ground level from reflectivities measured aloft. Several radar processing strategies, including nonadaptive, time-adaptive, and space-time-adaptive variants, have been implemented to assess the performance of these new algorithms. Reference rainfall data were derived from a careful analysis of rain gauge datasets furnished by the Cévennes-Vivarais Mediterranean Hydrometeorological Observatory. The assessment criteria for five intense and long-lasting Mediterranean rain events have proven that good quantitative precipitation estimates can be obtained from radar data alone within 100-km range by using well-sited, well-maintained radar systems and sophisticated, physically based data-processing systems. The basic requirements entail performing accurate electronic calibration and stability verification, determining the radar detection domain, achieving efficient clutter elimination, and capturing the vertical structure(s) of reflectivity for the target event. Radar performance was shown to depend on type of rainfall, with better results obtained with deep convective rain systems (Nash coefficients of roughly 0.90 for point radar-rain gauge comparisons at the event time step), as opposed to shallow convective and frontal rain systems (Nash coefficients in the $0.6-0.8$ range). In comparison with time-adaptive strategies, the space-time-adaptive strategy yields a very significant reduction in the radar-rain gauge bias while the level of scatter remains basically unchanged. Because the $Z-R$ relationships have not been optimized in this study, results are attributed to an improved processing of spatial variations in the vertical profile of reflectivity. The two main recommendations for future work consist of adapting the rain separation method for radar network operations and documenting $Z-R$ relationships conditional on rainfall type.
\end{abstract}

\footnotetext{
* Current affiliation: Department of Meteorology, University of Reading, Reading, United Kingdom.
}

Corresponding author address: Dr. Guy Delrieu, LTHE, UMR 5564 (CNRS, UJF, INPG, IRD), BP 53, F-38041, Grenoble CEDEX 9, France.

E-mail: guy.delrieu@hmg.inpg.fr

\section{Introduction}

Mountains induce a wide range of meteorological phenomena at the mesoscale, including the generation and intensification of precipitation. Furthermore, mountainous topography increases streamflow volumes and accelerates their concentration. These two factors place strong emphasis on the requirement for real-time estimation to 


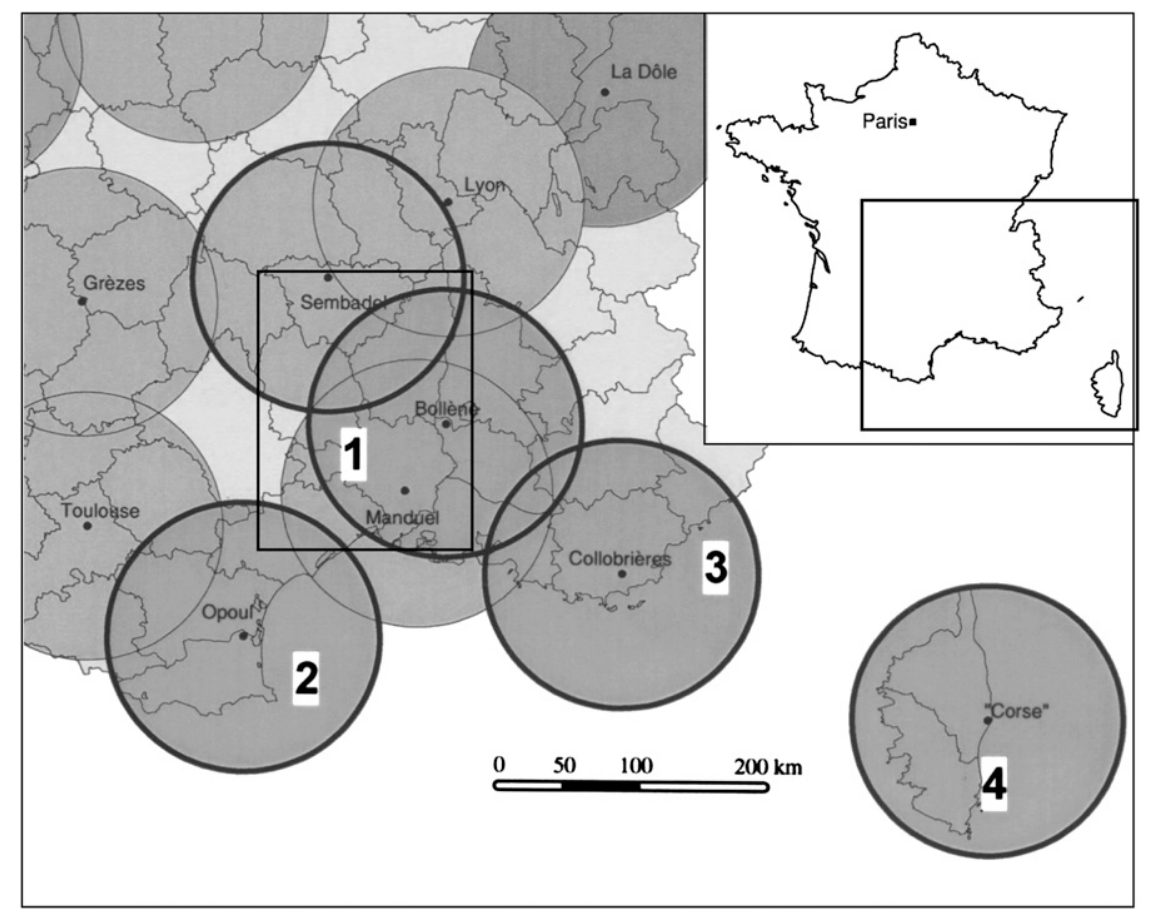

FIG. 1. Study area in southeastern France, with location of the four S-band weather radar systems (including 100-km range markers) deployed by Météo-France during the 1999-2004 period as a complement to the previous hydrometeorological coverage of the region. The Bollène radar system is number 1 . The inner black box delineates the CVMHO observation window.

mitigate flood and flash-flood hazards in such areas. A quantitative interpretation of the weather radar signal in terms of rainfall, however, is complicated because it depends on 1) rainfall variability over a range of scales, 2) the radar detection domain, which is constrained by both the surrounding relief and vertical structure of precipitation, and 3) the parameters and operating protocol of the radar system(s) employed. A pronounced relief obviously adds complexity to the radar quantitative precipitation estimation (QPE) problem by reducing radar visibility and increasing environmental sources of error. A number of authors have already addressed the specific subject of radar quantitative precipitation estimation in mountainous regions (e.g., Joss and Waldvogel 1990; Westrick et al. 1999; Young et al. 1999; Germann and Joss 2002; Pellarin et al. 2002; Dinku et al. 2002; Germann et al. 2006). Considerable research and operational efforts, however, are still required to optimize observation strategies and data-processing techniques.

Over the 1999-2004 period, the Arc Mediterranean Project performed by the Météo-France Application Radar à la Météorologie Infra-Synoptique (ARAMIS) radar network enabled installation of four new weather radar systems to improve the hydrometeorological coverage of southeastern France (see Fig. 1). This region is characterized by the presence of marked relief (Pyrenees, Massif Central, and Alps mountain ranges). The S-band radar systems in Bollène, Oppoul, and Collobrières, France, and Aléria, Corsica, complement the preexisting S-band and C-band systems located in Nîmes and Sembadel, France, respectively. The choice of S-band frequency is fully justified by the intense rain events that frequently occur during autumn, which result in destructive flash floods and flooding within the region (Jacq 1994; Rivrain 1998; Delrieu et al. 2005). The Bollène-2002 Experiment was designed by the Observation Systems Division of Météo-France (Météo-France/DSO), in cooperation with the Laboratoire d'étude des Transferts en Hydrologie et Environnement (LTHE), to start adapting operations and data processing of the new radar systems for hydrometeorological applications in such mountainous regions. For this purpose, an experimental volume-scan protocol was implemented for the Bollène S-band radar system during autumn of 2002. The Bollène-2002 Experiment and associated datasets will be described in section 2 of this paper.

These datasets served to develop a new radar QPE processing system for the ARAMIS network (Tabary 2007; Tabary et al. 2007) that has been implemented 
operationally since 2006. In conjunction with this system, LTHE has built a developmental radar QPE processing system called Traitements Régionalisés et Adaptatifs de Données Radar pour l'Hydrologie (Regionalized and Adaptive Radar Data Processing for Hydrological Applications), or TRADHy. The TRADHy strategy, focused on radar QPE from noncoherent volume-scanning data, consists of four steps. A preprocessing step is aimed at checking radar calibration stability, determining the detection domain (screening effects for each elevation angle), and characterizing dry-weather clutter and noise. During the course of a rain event, identifications are carried out to dynamically determine clutter, rain types, and the corresponding vertical profiles of reflectivity (VPR). Next, corrections for both clutter and screening effects, along with a projection of measured reflectivities onto the ground level using rain-type VPRs, are performed. As a final step, rainfall is estimated at ground level by considering a reflectivity-rain-rate conversion that depends on rain type. A strong constraint imposed herein is to use only radar data for such a processing sequence. In this article, reflectivity-rain-rate $(Z-R)$ relationships found in the literature will be considered instead of specific $Z-R$ relationships derived from drop size distribution measurements. No other meteorological data (e.g., radiosondes) will be used, for instance, to constrain VPR identification. Rain gauge measurements will be strictly reserved for assessing the radar QPE. Section 3 will provide a presentation of the TRADHy algorithms specifically adapted or developed during this study.

Various radar data-processing strategies will then be described in section 4 , along with their implementation conditions for the Bollène-2002 datasets. Herein we distinguish three types of strategies:

1) Nonadaptive strategies based on predefined products and/or parameterizations-for example, dry-weather clutter maps, climatological VPR, and $Z-R$ relationships (the operational processing strategy of the ARAMIS radar network in 2002 offered an example of such a robust yet inflexible approach),

2) Time-adaptive strategies for which the identification step is intended to identify a unique VPR assumed to be valid over the entire radar detection domain and in which the rainfall estimation also relies on a single $Z-R$ relationship [the operational radar processing strategy since 2006 (Tabary 2007) belongs to this category], and

3) Space-time-adaptive strategies, which consider regionalized processing by use of rain-type-based VPRs and $Z-R$ relationships determined automatically with the algorithms introduced in section 3 .
Section 5 is devoted to a performance evaluation of the various radar processing strategies for the Bollène2002 datasets. Assessing the quality of radar QPE is an important subject and one that has received major contributions over the past few decades [examples include the review papers by Wilson and Brandes (1979) and Joss and Waldvogel (1990)]. More recent contributions (e.g., Ciach and Krajewski 1999; Habib et al. 2004) have emphasized the problem of rain gauge representativeness in such evaluations, especially regarding short integration time steps. Because our objective in this article is to compare several radar data-processing strategies, a simple geostatistical approach (Creutin et al. 1988; Delrieu et al. 1988) to the assessment problem has been implemented, with reference rainfall being estimated from the dense network of rain gauges (Fig. 2) laid out by the Cévennes-Vivarais Mediterranean Hydrometeorological Observatory (CVMHO; Delrieu et al. 2005).

The conclusions of this study and recommendations for future work are presented in section 6 .

\section{The Bollène-2002 Experiment}

\section{a. Radar parameters and operations during the experiment}

Table 1 lists the set of Bollène radar system parameters, and Table 2 specifies the experimental scanning protocol implemented during autumn of 2002. The $0.8^{\circ}$, $1.2^{\circ}$, and $1.8^{\circ}$ plan position indicators (PPIs) were performed every $5 \mathrm{~min}$ to maintain the operational ARAMIS products in real time throughout the experiment. These were complemented by two sets of five PPIs, alternating every $5 \mathrm{~min}$, allowing for enhanced atmospheric sampling. The $0.4^{\circ}$ elevation angle was introduced to increase detection capability of the radar system toward and over the Mediterranean Sea in the southern sector. Antenna rotation speed was adapted depending on the elevation angle: $10^{\circ} \mathrm{s}^{-1}$ for the three operational elevation angles to improve the clutter identification technique operations and $15^{\circ} \mathrm{s}^{-1}$ for the remaining angles to meet the 5-min revisit time constraint. The Bollène radar remains a noncoherent, single-polarization system. The measured variables available for each $1-\mathrm{km}^{2}$ Cartesian mesh are 1) mean reflectivity, and 2) the mean absolute pulse-to-pulse reflectivity difference (MAD). Both variables are averaged over all individual polar sampling volumes, whose centers lie in the corresponding Cartesian mesh. The MAD variable represents the pulse-to-pulse variability of reflectivity and is used herein for clutter identification. It is defined as 

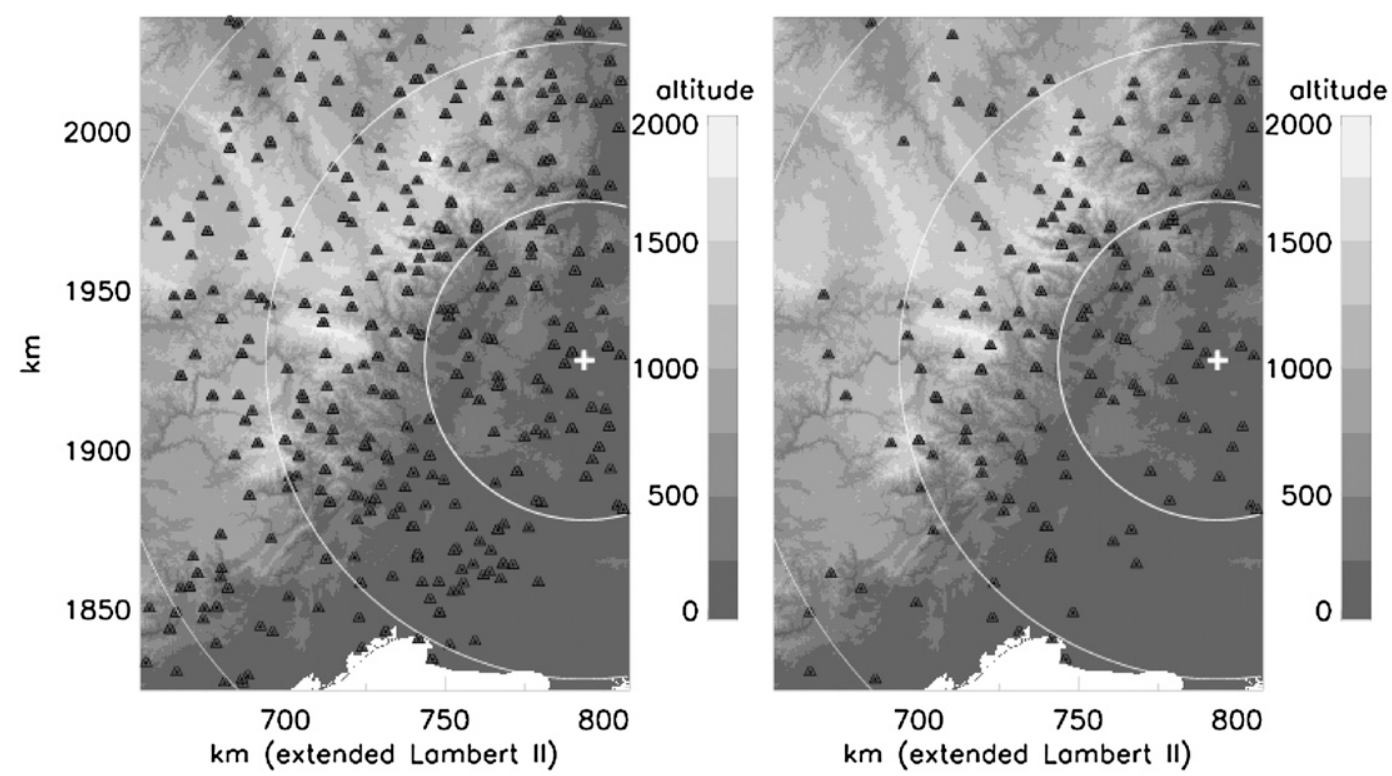

FIG. 2. Rain gauge networks available at both the (left) event time scale and (right) hourly time scale superimposed on the orography of the Cévennes-Vivarais region.

$$
\mathrm{MAD}_{i, n, N}=\frac{1}{N} \sum_{k=i-(N / 2)+1}^{i+(N / 2)}\left|Z_{k-(N / 2)}-Z_{k+(N / 2)}\right|,
$$

where $Z$ is the reflectivity value (dBZ), $i$ the pulse index, $n$ is the pulse separation, and $N$ is the number of consecutive estimates used to calculate the mean.

\section{b. Rain gauge networks and reference rainfall}

The rain gauge networks available for assessing the Bollène-2002 radar datasets are displayed in Fig. 2. Two networks containing some 500 daily rain gauges (Fig. 2a; density of approximately 1 rain gauge per 64 kilometers squared) and 160 hourly rain gauges (Fig. 2b, density on the order of 1 rain gauge per 200 kilometers squared) are available. These networks are operated by three different operational weather and hydrological services (Météo France, the Grand Delta Flood Prediction Unit, and the "EDF" electric utility) with diverse metrological objectives and practices. An important issue for the CVMHO therefore is to gather and critically analyze such datasets. For this purpose, a geostatistical data quality-control technique (Kirstetter 2008) has been implemented at the event time scale; this technique is based on the automatic detection of abnormal differences between rain amounts at neighboring rain gauges using the variogram function. For each interdistance class, the upper tail of the squared increment distribution of rain amounts is screened, which leads to a series of "suspect" measurements that are critically analyzed on an individual basis and may eventually be rejected during a second step. The kriging technique (Creutin and Obled 1982; Lebel et al. 1987) is then introduced to establish and select reference rainfall values. For this choice, we account for the kriging estimation variance as an indicator of reference rainfall accuracy (Delrieu et al. 1988). Note that the critical analysis of rain gauge data generally allows regularization of the variogram function at the origin with a reduction/suppression of the nugget effect. Because the aim of this article is to compare various radar processing techniques with one another, we have simply chosen herein to consider the kriging point estimates at the center of the $1-\mathrm{km}^{2}$ radar meshes containing a rain gauge as the set of reference

TABLE 1. Bollène radar system parameters.

\begin{tabular}{ll}
\hline \hline Type & MTO2000 \\
Location & Bollène \\
$x$ coordinate $(\mathrm{km}$, extended Lambert II) & 792.5 \\
$y$ coordinate $(\mathrm{km}$, extended Lambert II) & 1927.6 \\
Alt (m MSL) & 327.0 \\
Transmitter-receiver & \\
Peak power $(\mathrm{kW})$ & 600 \\
Frequency $(\mathrm{GHz})$ & 2.8 \\
PRF $(\mathrm{Hz})$ & 250 \\
Pulse width $(\mu s)$ & 2 \\
Min detectable signal MDS $(\mathrm{dBm})$ & -113 \\
Dynamic range $(\mathrm{dB})$ & 80 \\
Antenna & \\
Diameter $(\mathrm{m})$ & 6.2 \\
Beamwidth at half-power point $\left({ }^{\circ}\right)$ & 1.28 \\
Power gain $(\mathrm{dB})$ & 42.5 \\
Measured parameters (noncoherent radar) & $Z$, MAD in $Z$ \\
\hline
\end{tabular}


TABLE 2. Volume-scanning protocol implemented for the Bollène radar system during autumn 2002. The three PPIs in boldface are sampled every $5 \mathrm{~min}$ and served to establish the realtime operational products during the Bollène-2002 Experiment.

\begin{tabular}{cccccc}
\hline \hline $\begin{array}{c}\text { Cycle } \\
1\end{array}$ & $\begin{array}{c}\text { Elev } \\
\text { angle } \\
\left({ }^{\circ}\right)\end{array}$ & $\begin{array}{c}\text { Antenna } \\
\text { rotation } \\
\text { speed }\left({ }^{\circ} \mathrm{s}^{-1}\right)\end{array}$ & $\begin{array}{c}\text { Cycle } \\
2\end{array}$ & $\begin{array}{c}\text { Elev } \\
\text { angle } \\
\left({ }^{\circ}\right)\end{array}$ & $\begin{array}{c}\text { Antenna } \\
\text { rotation } \\
\text { speed }\left({ }^{\circ} \mathrm{s}^{-1}\right)\end{array}$ \\
\hline 1 & 0.4 & 15 & 1 & 17.0 & 15 \\
2 & 14.0 & 15 & 2 & 11.0 & 15 \\
3 & 9.0 & 15 & 3 & 7.2 & 15 \\
4 & 6.0 & 15 & 4 & 4.8 & 15 \\
5 & 3.6 & 15 & 5 & 2.4 & 15 \\
$\mathbf{6}$ & $\mathbf{1 . 8}$ & $\mathbf{1 0}$ & $\mathbf{6}$ & $\mathbf{1 . 8}$ & $\mathbf{1 0}$ \\
$\mathbf{7}$ & $\mathbf{1 . 2}$ & $\mathbf{1 0}$ & $\mathbf{7}$ & $\mathbf{1 . 2}$ & $\mathbf{1 0}$ \\
$\mathbf{8}$ & $\mathbf{0 . 8}$ & $\mathbf{1 0}$ & $\mathbf{8}$ & $\mathbf{0 . 8}$ & $\mathbf{1 0}$ \\
\hline
\end{tabular}

values. In-depth analyses and initial considerations regarding a radar QPE error model have been presented in Kirstetter (2008).

\section{c. Selected rain events}

Bollène radar system operations with the experimental volume-scan protocol were conducted over the September-December 2002 period, which was particu- larly wet and resulted in sampling several intense rain events typical of the northwestern Mediterranean climate. Table 3 summarizes the main characteristics of the five rain events selected for this study; these events cover a broad array of Mediterranean rain systems and span a total duration of $176 \mathrm{~h}$. The 8-9 September 2002 event was highly exceptional, with total rainfall amounts reaching $700 \mathrm{~mm}$ in $28 \mathrm{~h}$ as a result of a stationary, $\mathrm{V}$-shaped mesoscale convective system (MCS) affecting the Gard plains. This event caused 24 casualties and severe economic loss to the Gard region (Delrieu et al. 2005). The 21 October and 21 November 2002 rain events, with maximum accumulations of 60 and $100 \mathrm{~mm}$, respectively, correspond to the passage of cold fronts within westerly meteorological regimes. The 24 November and 10-13 December 2002 events (maximum rain amounts of 150 and $300 \mathrm{~mm}$, respectively) occurred in southerly meteorological regimes typical of the warmer sectors of Mediterranean cyclones; they are characterized by widespread and long-lasting rainfall with embedded convection triggered by the orography. Note that this dataset does not include snow events, which even in winter rarely occur in the Cévennes region.

As a further illustration of the magnitude and location of rain events, maps of the total rainfall amounts

TABLE 3. Main characteristics of the selected rain events. The figures listed relate to the rainfall observed at ground level over the CVMHO observation window.

\begin{tabular}{|c|c|c|c|c|c|}
\hline Date & $\begin{array}{l}\text { Location within } \\
\text { the CVMHO } \\
\text { window }\end{array}$ & $\begin{array}{l}\text { Spatial extension } \\
\text { (area over which } \\
\text { various rainfall } \\
\text { amounts are } \\
\text { exceeded) }\end{array}$ & $\begin{array}{l}\text { Max } \\
\text { rainfall } \\
\text { amount } \\
(\mathrm{mm})\end{array}$ & $\begin{array}{l}\text { Duration } \\
\text { of the } \\
\text { rain event } \\
\text { (h) }\end{array}$ & Meteorological features \\
\hline 8-9 Sep 2002 & Gard plains & $\begin{array}{l}>200 \mathrm{~mm}: \\
5500 \mathrm{~km}^{2} \\
>400 \mathrm{~mm}: \\
1800 \mathrm{~km}^{2}\end{array}$ & 700 & 28 & $\begin{array}{l}\text { Southwestern-southern regime; } \\
\text { stationary V-shaped MCS + } \\
\text { cold front; flash floods and } \\
\text { catastrophic flooding in the } \\
\text { Gard plains }\end{array}$ \\
\hline 21 Oct 2002 & $\begin{array}{l}\text { Ardèche watershed; } \\
\text { Rhone Valley }\end{array}$ & $\begin{array}{l}>20 \mathrm{~mm}: \\
15000 \mathrm{~km}^{2} \\
>50 \mathrm{~mm}: \\
1500 \mathrm{~km}^{2}\end{array}$ & 60 & 10 & $\begin{array}{l}\text { Western regime; cold front with } \\
\text { embedded convection }\end{array}$ \\
\hline 21 Nov 2002 & Ardèche watershed & $\begin{array}{l}>30 \mathrm{~mm}: \\
10000 \mathrm{~km}^{2} \\
>50 \mathrm{~mm}: \\
2000 \mathrm{~km}^{2}\end{array}$ & 100 & 22 & $\begin{array}{l}\text { Western regime; active cold } \\
\text { front with embedded } \\
\text { convection }\end{array}$ \\
\hline 24 Nov 2002 & $\begin{array}{l}\text { Cévennes Mountains; } \\
\text { Ardèche plains }\end{array}$ & $\begin{array}{l}>50 \mathrm{~mm}: \\
12000 \mathrm{~km}^{2} \\
>100 \mathrm{~mm}: \\
2000 \mathrm{~km}^{2}\end{array}$ & 150 & 48 & $\begin{array}{l}\text { Southern-southeastern regime; } \\
\text { widespread rainfall with } \\
\text { sometimes convective rainy } \\
\text { bands and varied orientations; } \\
\text { complex dynamics and } \\
\text { contrasted vertical development }\end{array}$ \\
\hline 10-13 Dec 2002 & $\begin{array}{l}\text { Cévennes Mountains; } \\
\text { Hérault plains }\end{array}$ & $\begin{array}{l}>100 \mathrm{~mm}: \\
10000 \mathrm{~km}^{2} \\
>200 \mathrm{~mm}: \\
1000 \mathrm{~km}^{2}\end{array}$ & 300 & 68 & $\begin{array}{l}\text { Southern regime stationary rain } \\
\text { event with widespread rainfall } \\
\text { of sustained intensity }\end{array}$ \\
\hline
\end{tabular}


observed on 8-9 September, 21 November, and 10-13 December 2002 are displayed in Fig. 3.

\section{Space-time-adaptive correction procedures}

This section will discuss the algorithms specifically developed during this study; these include 1) a dynamic clutter identification technique based on the pulse-topulse variability of reflectivity, 2) a procedure for the coupled identification of rain types (convective vs widespread rainfall) and their associated vertical profiles of reflectivity, and 3) an algorithm for estimating reflectivity at the ground level from reflectivities measured aloft. To illustrate this discussion, we have selected an example from the rain fields observed during the MCS on 8-9 September 2002 (see Figs. 4 and 5). The raw reflectivity data shown in Fig. 4a highlight the strong clutter contamination in such mountainous regions for the considered wavelength. Figure $4 \mathrm{~b}$ shows the corresponding MAD reflectivity data, which offer the potential for clutter identification with low MAD values for ground clutter and higher values in rain. Moreover, this case provides a good example of the strong spatial variations in rainfall exhibited within a single rain field: deep convection occurred on the southern branch of the V-shaped MCS while a stratiform precipitation trail formed northward (see Fig. 4d and the vertical cut displayed in Fig. 5b). The work presented here faces the challenge of taking this spatial heterogeneity of rainfall into account in radar data processing.

\section{a. Adaptive clutter identification and correction}

Figure 6 presents the conditional reflectivity means (i.e., the means calculated for reflectivity values greater than $12 \mathrm{dBZ}$ ) along with MAD values evaluated over a 10-day dry-weather dataset for two elevation angles. The mean reflectivity map for the low-elevation angle indicates that ground clutter is particularly strong in the vicinity of the radar site, as the result of sidelobe returns from the numerous infrastructure facilities (highways, railways, electric lines, etc.) in the Rhone Valley. At ranges between 50 and $100 \mathrm{~km}$, the Cévennes Mountains, located west of the Bollène radar, also produce intense radar returns due to interception of the main antenna lobe. This intense clutter is clearly associated with low mean MAD values (bottom-left panel in Fig. 6). Within the 100-km range and along the Rhone Valley, in addition to the intense ground clutter, a mostly uniform pattern of weak radar returns is associated with high mean MAD values. Such a pattern most likely stems from the clear-air echoes often observed before dawn and after dusk within the region. Both the mean re- flectivity and MAD maps yield additional sources of noise at greater ranges, including 1) radials in the southwest direction associated with sunset, and 2) interference between the Bollène and Nîmes radars. Note that both noise sources are associated with high MAD values, which complicates their detection. As the elevation angle increases (right panels in Fig. 6), noise associated with the relief is obviously reduced; however, contamination by aircraft flight paths becomes highly significant.

A method for detecting clutter based on the interpulse variability of noncoherent radar returns has been developed; it utilizes the MAD [see Eq. (1)], which reflects the degree of pulse-to-pulse variability of the reflectivity. Tests performed prior to the experiment served to select the antenna rotation speed, a suitable time separation between pulses $\left(t_{s}=n / \mathrm{PRF}\right)$ and the number of pulses $N$ to be averaged in the evaluation of the polar MAD values, which can then be averaged over the $1-\mathrm{km}^{2}$ Cartesian meshes. The values of $10^{\circ} \mathrm{s}^{-1}$, $t_{s}=8 \mathrm{~m} \mathrm{~s}^{-1}(n=2)$, and $N=40$ were found to be appropriate with respect to the radar parameters and operating protocol described in Tables 1 and 2.

Parameterization of the adaptive clutter identification method was then empirically defined, based on an analysis of the clutter characteristics during both dry weather and rain events. This procedure, consisting of three steps, has been summarized in Table 4. The first step introduces a combination of predefined clutter maps observed during dry days (Fig. 6) and the MAD measurements at the time at which the identification is to be performed. Four clutter categories were established: three of them correspond to persistent clutter and the last category corresponds to sporadic clutter defined with respect to a dry-weather occurrence threshold value. For the sporadic-clutter case, the pixels with MAD $<3 \mathrm{~dB} Z$ have been flagged as clutter. For the persistent-clutter cases on the other hand, a stratification of MAD thresholds (see Table 4) as a function of dry-weather MAD values proved to be effective in discarding fewer measurements of precipitation when dominant over clutter. As a second step, all measurements directly adjacent to clutter identified by their MAD values are removed if a maximum local reflectivity gradient exceeds a given threshold; this step is related to the fact that strong gradients are often present at the edge of ground-cluttered regions because of antenna movement over the target. Such gradients artificially increase the MAD values, inhibiting clutter detection. A third step was deemed necessary to remove clutter for screened or isolated pixels (e.g., associated with aircraft or interference).

An interpolation scheme was then applied to fill in the ground-cluttered regions. Because of the large size of 

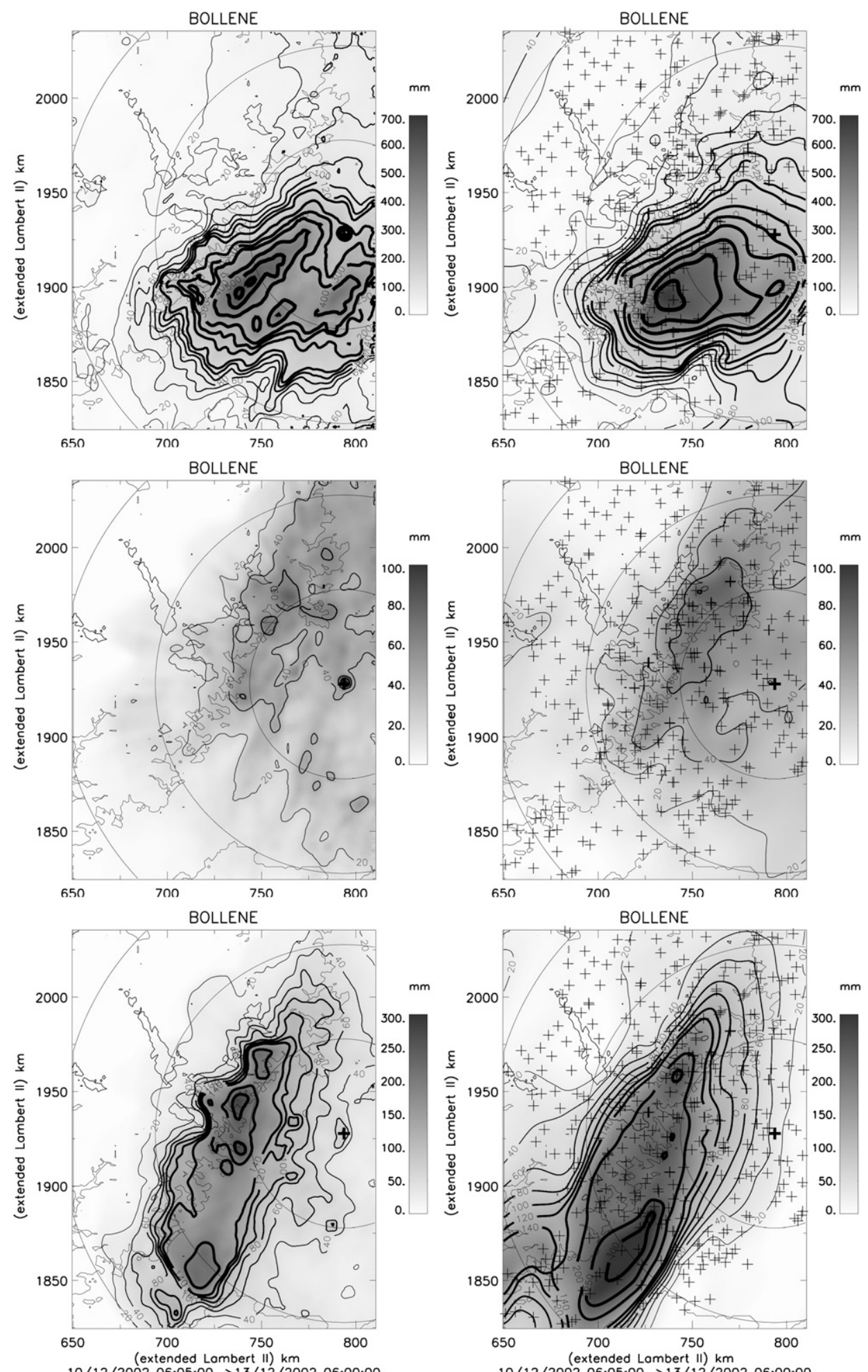

10/12/2002 06:05:00->13/12/2002 06:00:00

10/12/2002 06:05:00->13/12/2002 06:00:00

FIG. 3. Rainfall fields at the event time scale over the CVMHO window for the rain events of (top) 8-9 Sep, (middle) 21 Nov, and (bottom) 10-13 Dec 2002. (right) The kriging interpolation technique with anisotropic variograms was used to derive the rain gauge maps. (left) Results of the ST-AD3 radar processing strategy (see section 4a) are displayed with radar range markers every $50 \mathrm{~km}$. Note that the gray scales and isolines have been adapted to the magnitude of each rain event. 

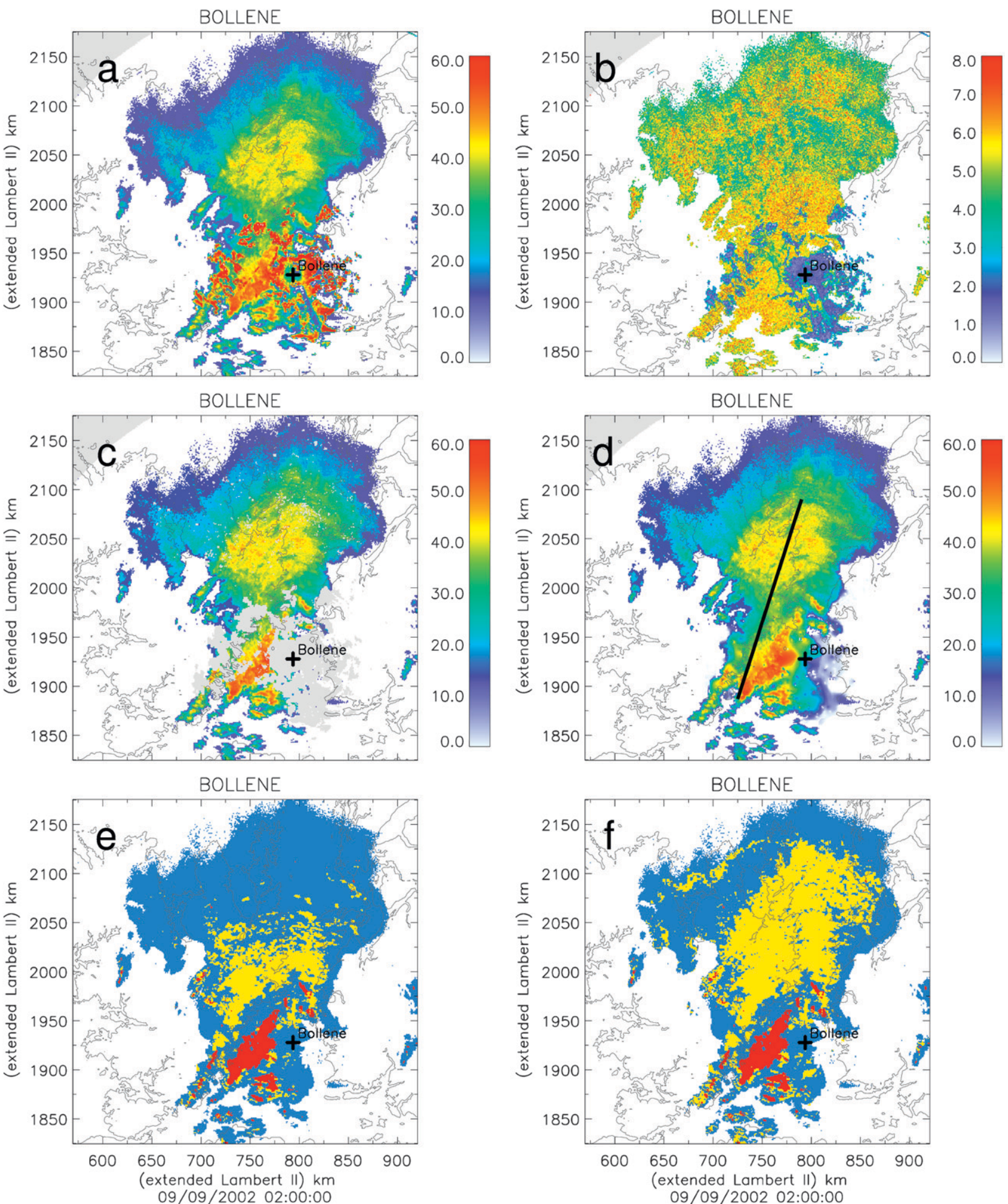

FIG. 4. Case of the MCS observed at 0200 UTC 9 Sep 2002: (a) raw mean reflectivity, (b) MAD in reflectivity values, (c) mean reflectivity after ground clutter identification, (d) mean reflectivity after interpolation, (e) results of the first step of the rain separation (red: convective rainfall; yellow: stratiform rainfall; blue: undetermined), and (f) results of the final rain separation [same convention as in (e)]. Note that (a)-(d) correspond to reflectivity and MAD measurements for the $0.8^{\circ}$ elevation angle, whereas (e) and (f) are maps of rain types determined using the full-volume data. 


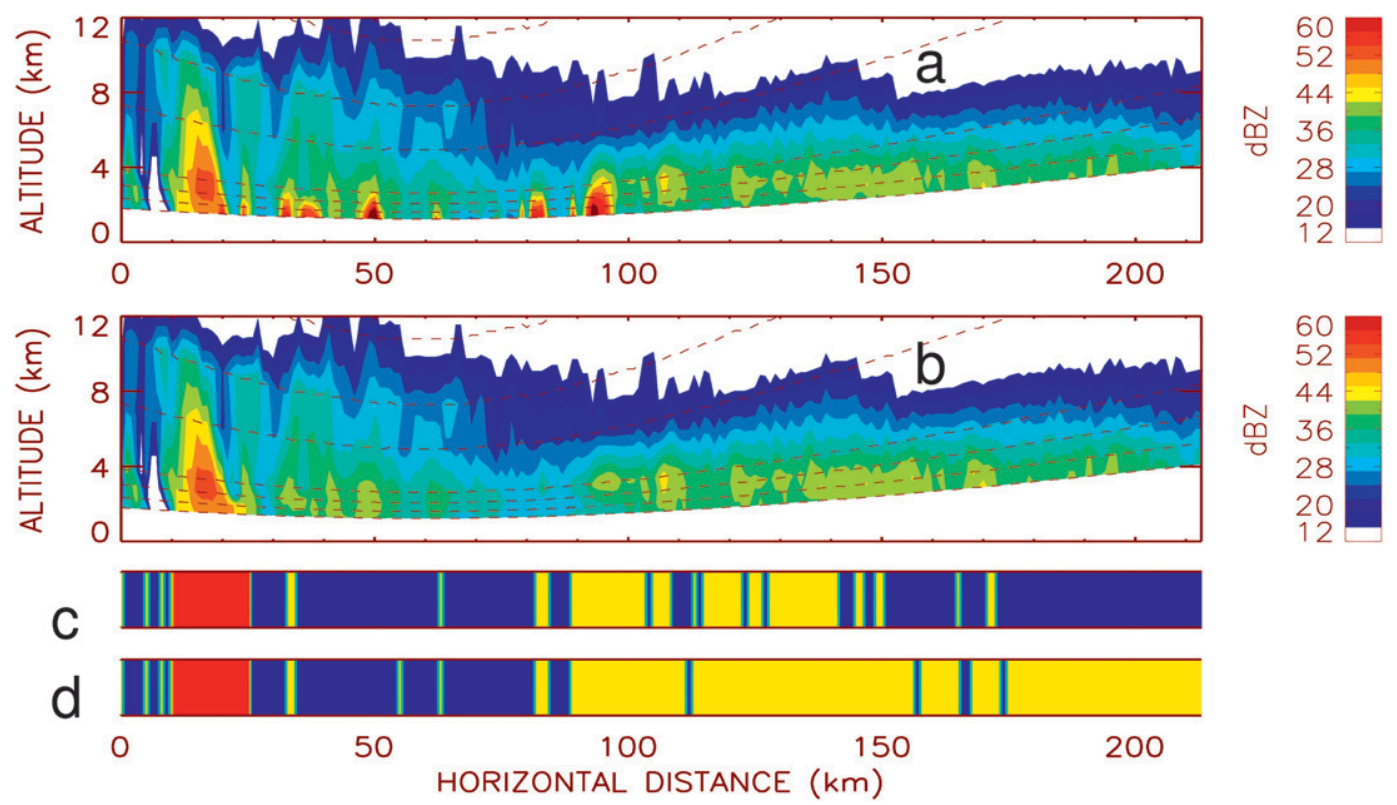

FIG. 5. Vertical cuts in the volume radar data at 0200 UTC 9 Sep 2002 along the line shown in Fig. 4d: (a) raw mean reflectivity, (b) mean reflectivity after clutter identification and interpolation, (c) colored bands indicating results from the first rain-type separation (red: convective rainfall; yellow: widespread rainfall; blue: undetermined), and (d) colored band indicating results from the final rain separation [same convention as in (c)].

such regions for the low elevation angles (e.g., Fig. 4c), this point received special attention; the interpolation procedure ultimately selected is described in Table 4.

The operation of the clutter identification and correction steps is illustrated for the 9 September 2002 example in Figs. 4c, 4d, 5a, and 5b. Although largely heuristic, this technique was found to provide good results, which will be assessed in a more quantitative context in section 5 .

\section{b. Coupled rain type and VPR estimation}

The attempt to regionalize the radar data-processing scheme requires implementing automatic rain separation techniques. Because velocity data are not available with the noncoherent radar system employed, we will rely hereinafter on algorithms developed for use with $3 \mathrm{D}$ reflectivity data alone. To be more specific, the algorithms proposed by Steiner et al. (1995) for identifying convective cells and by Sánchez-Diezma et al. (2000) for detecting the bright band, which is indicative of stratiform rainfall, were implemented with slight alterations. Chapon (2006) developed a decision tree for the synergy of these two algorithms, and this tree will be described in section $3 b(1)$. The problem of VPR estimation conditional upon rain type will be addressed in section $3 b(2)$. Various estimators will be considered with both of the following: 1) the so-called apparent
VPR (i.e., the VPR estimated by averaging measured reflectivity values close to the radar site) as proposed by Germann and Joss (2002) for instance and 2) the socalled inversion VPR, in accordance with the inversion technique proposed by Andrieu and Creutin (1995) and further developed by Vignal et al. (1999). The inversion approach seeks to correct for radar sampling effects in the VPR estimation. It has been adapted by Kirstetter (2008) to the case of time-varying geographical regions defined by the rain separation technique. After implementation, it was found that the rain separation algorithms exhibit inherent limitations, especially over longer ranges, because of the radar sampling properties. These effects are certainly difficult to integrate into the current formulation of separation algorithms. To overcome this difficulty, we will propose a procedure in section $3 b$ (3) for the coupled identification of rain type and corresponding VPRs.

\section{1) Preliminary RAin SEPARATION}

Steiner et al. (1995) proposed a well-known approach for identifying convective precipitation using three criteria. The first two criteria are intended to identify the centers of convective cells. The first consists of a reflectivity threshold above which it is assumed that precipitation can only result from convective processes. The second features a peakedness criterion: a pixel is 


\section{Conditional mean reflectivity (dBZ)}
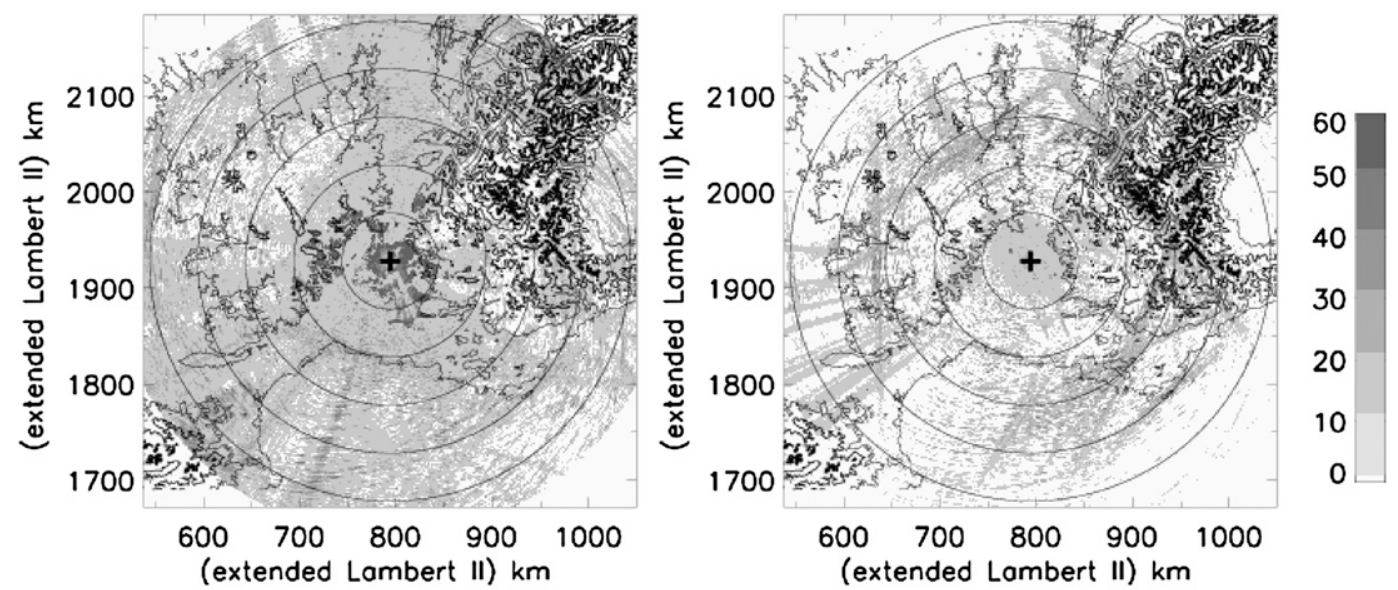

\section{Conditional mean MAD (dBZ)}
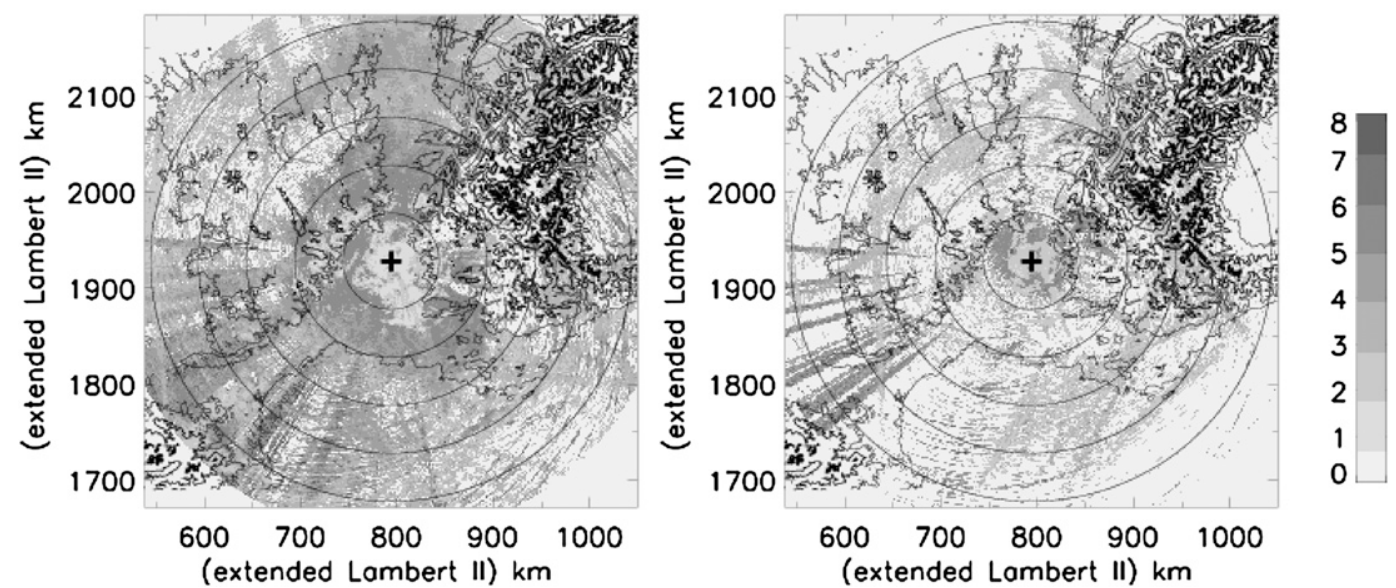

FIG. 6. Dry-weather clutter characteristics for the (left) $0.8^{\circ}$ and (right) $3.6^{\circ}$ PPIs derived from a sample of 10 days during the Bollène-2002 Experiment. The conditional means are estimated by using a threshold value of $12 \mathrm{~dB} Z$ for the reflectivity.

assumed to be a convective center if the reflectivity value exceeds the conditional mean reflectivity determined over a surrounding region (termed "background reflectivity") from a given reflectivity difference $\Delta Z$ $(\mathrm{dB} Z)$. The third criterion defines a convective region associated with and surrounding each pixel, identified as a convective center using one of the first two criteria. Sánchez-Diezma et al. (2000) proposed a method for identifying the bright band with volume-scan radar data as an indicator of stratiform precipitation. The method screens the vertical profiles of measured reflectivity for a peak exceeding a given reflectivity difference $\Delta Z_{\mathrm{BB}}$, with respect to the reflectivity values both above and below the peak. Two iterations are performed. The first searches for intense peaks $\left(\Delta Z_{\mathrm{BB}}>5 \mathrm{dBZ}\right)$ over the entire altitude range, and the second refines the determination of spatial extension of the bright band by considering a reduced peak $\left(\Delta Z_{\mathrm{BB}}>2 \mathrm{dBZ}\right)$ over an altitude range around the average brightband altitude, as determined from the previous step.

Both algorithms were implemented "as is" for the Bollène-2002 radar dataset. As suggested by Steiner et al. (1995), their adjustment/evaluation was introduced by means of visual inspection of the results in both the horizontal and vertical planes for the specific radar dataset. Based upon completion of this initial task, the following comments can be made:

1) The sensitivity study on Steiner's algorithm showed that it functions better when applied to individual 
TABLE 4. Parameterization of the clutter identification and interpolation technique: $\overline{M A D_{\mathrm{dry}}(j)}$ is the conditional mean of dry-weather clutter for a given Cartesian pixel $j, \operatorname{MAD}(j, t)$ is the rain $\operatorname{MAD}$ value at time $t$, and $\operatorname{MaxAMD}(j, t)$ is the maximum local gradient evaluated from the $1-\mathrm{km}^{2}$ Cartesian reflectivity field.

\begin{tabular}{|c|c|}
\hline Identification & Pixel flagged as clutter if the following conditions are met: \\
\hline \multicolumn{2}{|c|}{ Step 1: Based on dry-weather (DW) and rain MAD values } \\
\hline Persistent clutter 1: DW occurrence $\geq 3 \%$ & $\overline{M A D_{\mathrm{dry}}(j)}<1.8 \mathrm{~dB} Z$ and $\operatorname{MAD}(j, t)<5.5 \mathrm{dBZ}$ \\
\hline Persistent clutter 2: DW occurrence $\geq 3 \%$ & $1.8 \leq \overline{M A D_{\text {dry }}(j)}<2.1 \mathrm{~dB} Z$ and $\operatorname{MAD}(j, t)<4.5 \mathrm{~dB} Z$ \\
\hline Persistent clutter 3 : DW occurrence $\geq 3 \%$ & $2.1 \mathrm{~dB} Z \leq M A D_{\mathrm{dry}}(j)$ and $\operatorname{MAD}(j, t)<3.5 \mathrm{dBZ}$ \\
\hline Sporadic clutter: DW occurrence $<3 \%$ & $\operatorname{MAD}(j, t)<3.0 \mathrm{dBZ}$ \\
\hline \multicolumn{2}{|l|}{ Step 2: Based on reflectivity gradients } \\
\hline & $\begin{array}{l}\text { For the } 8 \text { pixels surrounding a pixel flagged as clutter: if MaxAMD }> \\
6 \mathrm{~dB} \mathrm{~km}^{-1} \text {, the pixel is flagged as clutter as well }\end{array}$ \\
\hline \multicolumn{2}{|l|}{ Step 3: Based on additional criteria } \\
\hline & $\begin{array}{l}\text { If a pixel is flagged as clutter at a given elevation, all of the lowest-elevation } \\
\text { pixels will be flagged as clutter; Isolated pixels (one single reflectivity } \\
\text { value greater than or equal to } 12 \mathrm{~dB} Z \text { over the vertical) are flagged } \\
\text { as clutter }\end{array}$ \\
\hline \multicolumn{2}{|r|}{ as ciutur } \\
\hline & $\begin{array}{l}\text { Reflectivity values are averaged by considering inverse-distance weights } \\
\text { (to limit bias, the average is actually computed over } Z^{1 / b} \text { values } \\
\text { ( } Z \text { : } \mathrm{mm}^{6} \mathrm{~m}^{-3} \text {, where } b \text { is the exponent of the } Z-R \text { relationship set } \\
\text { equal to } 1.5 \text { in this context); Cartesian neighborhoods of increasing } \\
\text { order [1) } 8 \text { surrounding pixels; } 2 \text { ) } 24 \text { pixels surrounding pixels, etc.] } \\
\text { are successively screened; for a given order, the interpolated value is } \\
\text { calculated only if noninterpolated values are available for over } 50 \% \\
\text { of the pixels; a maximum order of } 4 \text { will be considered }\end{array}$ \\
\hline
\end{tabular}

PPIs rather than to $2 \mathrm{D}$ composites of the radar volume data (CAPPIs, vertical projections of the maximum reflectivity, etc.). Such composite products mix vertical and horizontal reflectivity gradients and, as a consequence, prove to be inappropriate.

2) In some instances, the algorithm was found to produce spurious identification of convection at the brightband altitude in stratiform regions. These erroneous detections resulted from criterion 1 , and the application of criterion 3 significantly exacerbated the problem.

3) A detailed analysis of the utility of the three criteria indicated that criteria 1 and 2 act in a complementary manner. Criterion 2 allows detecting smaller convective cells at high elevation angles and/or over long ranges. The reflectivity difference function, which depends on the background reflectivity value, appears to be effective in partially accounting for the decrease in reflectivity as a function of altitude, a fact not taken into account in criterion 1 . Furthermore, it was found that criterion 3 introduced pixels with very noisy reflectivity data.

4) The brightband detection capability of the SánchezDiezma algorithm depended heavily on the scanning protocol (number and values of elevation angles) as well as on the brightband altitude itself. This capability decreases significantly at longer range because of the increase in both radar sampling volume and aboveground altitude, along with the reduced number of vertical samples.

The rain separation algorithm implemented can be summarized as follows: The 5-min volume radar reflectivity dataset is preprocessed for clutter and screening effects. The Sánchez-Diezma algorithm is then applied with its original parameterization to determine mean altitude of the bright band and the geographical domain it encompasses. The Steiner algorithm is applied to each individual PPI separately, regardless of results from the stratiform algorithm. In comparison with the original version, two additional modifications have been implemented: 1 ) the reflectivity threshold of criterion 1 is set at $43 \mathrm{dBZ}$ (instead of $40 \mathrm{dBZ}$ ) and 2) criterion 3 has been removed. A decision tree can now be considered for categorizing each Cartesian pixel, based on results from the convective algorithm for all elevation angles and on brightband detection results:

1) If at least $N_{\mathrm{cd}}$ convective detections (out of the 8 elevation angles) are found outside an altitude range of $\pm 0.5 \mathrm{~km}$ around the identified brightband altitude, the pixel is then classified as convective. The $N_{\mathrm{cd}}$ threshold depends on the radar operating protocol and is empirically related to the number of 

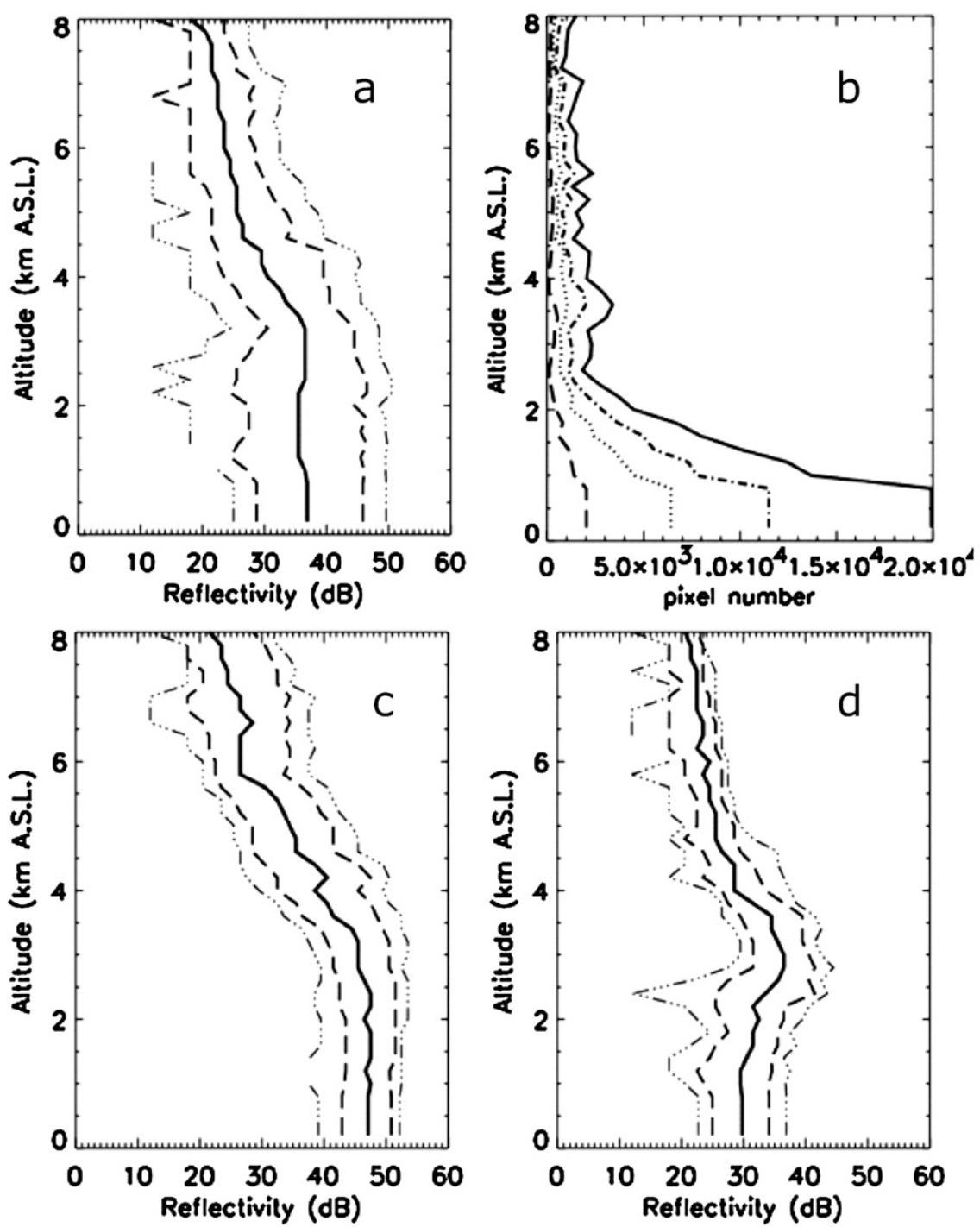

FIG. 7. Illustration of the 3D variability of the measured reflectivity within $60 \mathrm{~km}$ of the radar for the 0200 UTC 9 Sep 2002 case, showing the measured reflectivity PDFs as a function of altitude for (a) all rainy pixels, (c) convective pixels, and (d) stratiform pixels (solid line: median value; dashed lines: $20 \%$ and $80 \%$ quantiles; dash-dotted lines: $10 \%$ and $90 \%$ quantiles). (b) The sampling sizes (continuous: all rain pixels; dotted: convective; dashed: widespread; dash-dotted: undetermined). PDFs are established with observations performed between 0100 and 0200 UTC $(1 \mathrm{~h})$.

elevation angles lying outside the brightband region, as a function of range. Typical values considered for the Bollène-2002 operating protocol (see Table 2) are $4,3,2$, and 1 for the range classes $0-20,20-40$, $40-150$, and $>150 \mathrm{~km}$, respectively.

2) Should brightband detection be identified for a given pixel not already classified as convective, it is flagged as being stratiform. Furthermore, an undetermined pixel at a given time step, for which brightband detection had been found during a previous time step, is also considered to be stratiform; this iden- tification allows us to take advantage of the twocycle scanning strategy implemented during the Bollène-2002 Experiment.

\section{2) VPR ESTIMATION CONDITIONAL UPON RAIN TYPE}

Figure 7 illustrates the variability in 3D reflectivity as well as the impact of the rain separation technique for the example at 0200 UTC 9 September 2002. The graphs display different quantiles of the probability 
density functions (PDF) for reflectivity measured as a function of altitude within $60 \mathrm{~km}$ of the radar. By convention, a radar pixel is considered to be rainy if the average measured reflectivity below an altitude of $1 \mathrm{~km}$ exceeds $20 \mathrm{~dB} Z$. To establish unconditional PDFs for the rainy pixels as a function of altitude, the measured reflectivity values below the lowest quantization level (12 $\mathrm{dBZ}$ in this case) at altitudes greater than $1 \mathrm{~km}$ were artificially set at $0 \mathrm{~dB} Z$. Figure 7 shows the wide spread in reflectivity PDFs for the entire set of rainy pixels (e.g., a $20 \%-80 \%$ interquantile range of $23 \mathrm{~dB}$ for $h=2 \mathrm{~km}$, where $h$ is altitude). The rain separation algorithm performs an efficient sort, in leading to reduced interquantile intervals (e.g., $20 \%-80 \%$ interquantile ranges of 8 and $15 \mathrm{~dB}$, for the convective and stratiform PDFs, respectively, at the same altitude) in addition to distinct median profiles (e.g., median values of 48 and $33 \mathrm{dBZ}$ for the convective and stratiform PDFs, respectively). Note that the stratiform and convective reflectivity PDFs proved to be very similar for the 10- and 60-min time intervals (not shown here). This apparent stability in time of the reflectivity PDFs has been used to consider for the VPR estimation spacetime domains extending over the 1 -h period prior to the time of interest.

We define the normalized VPR (NVPR) $\overline{z(h)}$ as the ratio of expected reflectivity values at a given $h$ and at a reference altitude $h_{0}$ close to the ground, over a given space-time domain:

$$
\overline{z(h)}=\frac{E[Z(h)]}{E\left[Z\left(h_{0}\right)\right]} .
$$

This definition generates four comments: 1) The VPR function characterizes the mean variability of the reflectivity field from a vertical perspective. Rainfall heterogeneity results from complex microphysical processes, and variability around the VPR function is likely to be strong. 2) One practical problem in VPR estimation lies in the fact that measured reflectivity values integrate the VPR over a given altitude range. Averaging measured reflectivities produces increasingly smoother VPR functions as the radar range increases. 3) In accordance with Andrieu and Creutin (1995), we are considering a normalized function for the VPR. In so doing, it becomes implicitly assumed that reflectivity can be expressed as the product of its value at ground level and the NVPR value at the considered altitude. From a practical point of view, the NVPR can then be used as a "transfer function," thereby allowing for deconvolution of the measured reflectivity profile and its extrapolation to ground level. 4) The ratio of the expectation values proposed in Eq. (2) has proven to be much less sensitive to extreme (and sometimes spurious) reflectivity values than the expectation from normalized reflectivities.

The normalized apparent VPR is one type of estimator for the NVPR defined in Eq. (2), as obtained by averaging measured reflectivities. We have introduced the following expression:

$$
\overline{z_{a}^{*}\left(h_{i}\right)}=\frac{\left[\sum_{j=1}^{N\left(h_{i}\right)} w_{i j}\left(h_{1}-h_{i}\right) Z_{m j}\left(h_{1}\right)\right] /\left[\sum_{j=1}^{N\left(h_{i}\right)} w_{i j}\left(h_{1}-h_{i}\right)\right]}{\left[\sum_{j=1}^{N\left(h_{i}\right)} w_{0 j}\left(h_{2}-h_{0}\right) Z_{m j}\left(h_{2}\right)\right] /\left[\sum_{j=1}^{N\left(h_{i}\right)} w_{0 j}\left(h_{2}-h_{0}\right)\right]}
$$

The apparent VPR is discretized into a number of altitude classes (in this case 60, with a 200 -m increment). The normalization term in the denominator of Eq. (3) includes measured reflectivity values observed in the socalled reference altitude range $h_{0}$, set here equal to $0-1 \mathrm{~km}$ MSL. The terms $Z_{m j}\left(h_{1}\right)$ and $Z_{m j}\left(h_{2}\right)\left(\mathrm{mm}^{6} \mathrm{~m}^{-3}\right)$ are the reflectivities measured at a given moment and location (symbolized by subscript $j$ ) observed above and within the reference altitude range, respectively. Note that estimating the numerator and denominator of Eq. (3) strictly with the subset of $N\left(h_{i}\right)$ observations simultaneously available for the two altitude classes $h_{i}$ and $h_{0}$ constitutes an important condition to avoid biasing the NVPR. The weights $w_{i j}$ are determined with the Gaussian approximation for the normalized power gain pattern of the antenna. By this procedure, a reflectivity measurement is actually distributed over a number of altitude classes, depending on both the antenna characteristics and measurement range. This physically based averaging procedure assigns greater weight to the radar measurements performed close to the radar site.

The VPR inversion method, initially proposed by Andrieu and Creutin (1995) and Andrieu et al. (1995) and then further developed by Vignal et al. (1999), has 

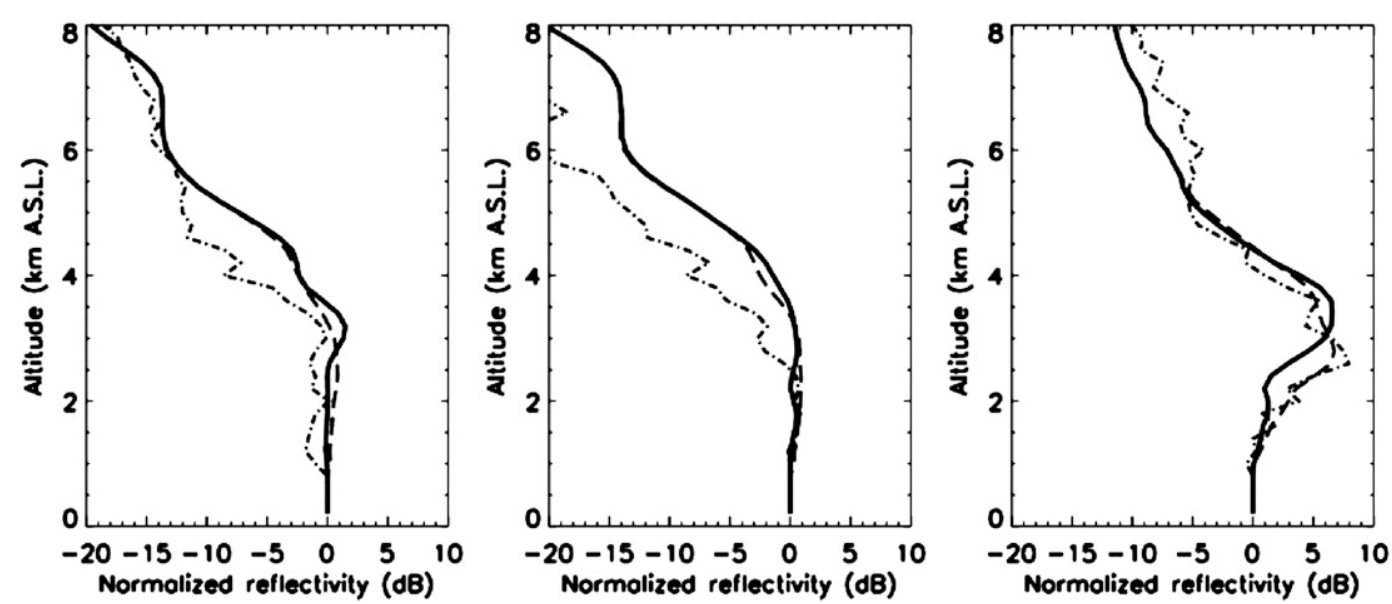

FIG. 8. Normalized vertical profiles of reflectivity (dB) for the 0200 UTC 9 Sep 2002 case. Each panel presents 1) the median profile normalized by the average reflectivity value within the first kilometer above sea level (dash-dotted line), 2) the apparent NVPR determined by means of the radar beamwidth weighting function (dashed line), and 3) the inversion NVPR (thick solid line). The panels correspond to NVPRs estimated using (left) all of the rainy pixels, (middle) the convective pixels, and (right) the stratiform pixels. VPR estimations are based on observations performed between 0100 and 0200 UTC $(1 \mathrm{~h})$. The median and apparent profiles have been established using reflectivity measurements within $60 \mathrm{~km}$ of the radar, and the inversion VPR estimation utilizes reflectivity measurements within $120 \mathrm{~km}$ of the radar for the CVMHO window.

been adapted within the context of this study to the case of time-varying geographical regions (Kirstetter 2008). We recall herein that the method runs with measured reflectivity ratios $\mathbf{q}$ linked to the NVPR by a nonlinear model denoted $\mathbf{q}=m(\overline{\mathbf{z}})$, where $\mathbf{z}$ is the vector of the discretized NVPR. The method determines the NVPR demonstrating the best compromise with respect to the maximum likelihood between fitting the measured reflectivity ratios and staying close to an a priori guess. The apparent NVPR thus serves as this a priori guess. Once the ratio has been conditioned, the NVPR is obtained by maximizing the following expression:

$$
\begin{aligned}
\Phi(\mathbf{z}, \mathbf{q})= & \left(\overline{\mathbf{z}}-\overline{\mathbf{z}}_{0}\right)^{\mathrm{T}} \mathbf{C}_{\mathbf{z}}^{-1}\left(\overline{\mathbf{z}}-\overline{\mathbf{z}}_{0}\right) \\
& +\left(\mathbf{q}-\mathbf{q}_{0}\right)^{\mathrm{T}} \mathbf{C}_{\mathbf{q}}^{-1}\left(\mathbf{q}-\mathbf{q}_{0}\right),
\end{aligned}
$$

where $\mathbf{q}_{0}$ is the vector of the observed ratios and $\overline{\mathbf{z}}_{0}$ is an a priori guess for the NVPR. The terms $\mathbf{C}_{\mathbf{z}}$ and $\mathbf{C}_{\mathbf{q}}$ are the covariance matrices of the NVPR and observed ratio components, respectively (the exponents -1 and $\mathrm{T}$ denote the inverse and transpose, respectively). Their specification allows establishing a balance in terms of confidence between data (i.e., ratios) and a priori information. Despite the fact that the VPR homogeneity assumption is more fully satisfied using the rain separation algorithm (Fig. 7), adapting the inversion technique to the case of variable geographic domains still proved to be challenging relative to previous implementations based on fixed spatial domains (Andrieu et al. 1995; Vignal et al. 1999, 2000; Vignal and Krajewski
2001). Two conditions ultimately allowed for robust inversions to be achieved: 1$)$ aggregating data from several successive $(1 \mathrm{~h})$ time steps and 2$)$ implementing a ratio data-censoring approach.

Figure 8 displays the median, apparent, and inversion NVPRs computed for the 0200 UTC 9 September 2002 case. The apparent and inversion NVPRs deviate significantly from the normalized median VPR toward higher values, which stems from both skewed reflectivity distributions and the influence of high (and occasionally spurious) reflectivity values. In addition, because the a priori VPR used in the inversion technique is the apparent NVPR, a comparison between the two functions serves to assess the inversion technique impact. As would be expected, the convective inversion NVPR is close to the apparent one, and the stratiform inversion NVPR shows a narrower and higher bright band; this result is consistent with simulations of beamwidth-smoothing effects versus range. A measure offering better representation of the NVPR with the inverse method, as compared with the apparent NVPR, can be obtained by evaluating the ability of the two functions to reproduce the observed ratios. Even though this improved fit is systematically observed, this finding does not necessarily imply that the correction using the inversion NVPR will outperform the one using the apparent NVPR. Because of the associated computational costs, it will be an important issue to assess the impact of the VPR estimation method in terms of radar QPE in section 5 . 


\section{3) REFINED RAIN TYPING}

It was considered to be a potentially interesting prospect to improve rain separation by introducing the NVPRs estimated during the previous step. To proceed, we started by generating apparent NVPRs as a function of range from the inversion NVPRs. The purpose of this step was to account for both the discrete number of vertical samples and beam-smoothing effects. Second, for the pixels remaining undetermined, we compared the local apparent VPR with range-dependent apparent NVPRs produced using a correlation criterion. Several trials were performed, and this proved the method to be very sensitive because of the small number of comparison points (i.e., a maximum of eight values). Our best method so far has consisted of extending stratiform region detection by considering a threshold of 0.95 on the correlation coefficient between the local and generated VPRs. Attempts to extend convective region detection have failed, an outcome that is consistent with the observation of very high variability in reflectivity for pixels determined as being convective with the third Steiner criterion.

Rain separation results for the 0200 UTC 9 September 2002 case are presented in the horizontal plane in Figs. $4 \mathrm{e}$ and $4 \mathrm{~d}$ and with colored bands (Figs. $5 \mathrm{c}, \mathrm{d}$ ) for the vertical cut in Fig. 5. Both the convective and stratiform regions are well depicted within $100 \mathrm{~km}$ of the radar for this case. The procedure of excluding convective detections over ranges corresponding to the brightband altitude proved to be very effective in eliminating erroneous convective detections in stratiform regions. Adapting the number of convective detections $N_{\text {cd }}$ depending on the range was also found to significantly improve convective algorithm performance over all ranges. For the case considered herein, the stratiform regions are considerably and very consistently extended according to the refined rain-typing step. It is clear, however, from implementation of the separation algorithm to the entire Bollène-2002 dataset that this result cannot be generalized. From our experience, the validity of the rain separation algorithm is likely to be limited to a range of $100 \mathrm{~km}$ at best, for this specific radar system.

\section{c. Reflectivity extrapolation at ground level}

Once the rain types and VPRs have been identified, the issue of establishing a $2 \mathrm{D}$ rain intensity product from 3D volume reflectivity data can be addressed. This discussion entails two aspects: 1) estimation of reflectivity close to the ground from a given elevation angle measurement or a combination of measurements available at various elevation angles and 2) application of a
$Z-R$ relationship for processing the reflectivity-rain-rate conversion. We shall address the first point here by means of the following method. For each radar pixel and each elevation angle, we account for screening effects, NVPR, and radar resolution volume characteristics to determine a correction factor for the reflectivity extrapolation at ground level. A simplified expression of this correction factor may be written as (Pellarin et al. 2002)

$$
\mathrm{CF}=K \iint_{\theta, \varphi} I(r, \theta, \varphi) f^{4}(\theta, \varphi) \overline{z(r \cos \theta)} \sin \theta d \theta d \varphi,
$$

where $(r, \theta, \varphi)$ are spherical coordinates relative to the radar location, $K$ is a constant dependent on the $3-\mathrm{dB}$ beamwidth, and $f^{4}(\theta, \varphi)$ is the two-way normalized power-gain function of the radar antenna. The function $I(r, \theta, \varphi)$ represents the power losses due to screening effects at the considered range and elevation angle. This function has been evaluated numerically by employing the procedure described by Delrieu et al. (1995). The corrected reflectivity $Z_{c}$ is then obtained as a function of measured reflectivity $Z_{m}$ as follows:

$$
Z_{c}=\mathrm{CF} \times Z_{m} .
$$

We then propose use of a weighted average of the corrected reflectivities observed vertically with the following formulation for the weights $\left\{w_{i}, i=1, N_{e}\right\}$ :

$$
w_{i}=\left[1 / \operatorname{Max}\left(\mathrm{CF}_{i}, 1 / \mathrm{CF}_{i}\right)\right]^{2},
$$

where Max is the "maximum value of" function and $\mathrm{CF}_{i}$ is the correction factor relative to the $i$ th elevation angle. The $N_{e}$ is the number of elevation angles available, with a subset of the eight elevation angles potentially available since various thresholds are considered so as to exclude measurements influenced by clutter and screening effects. This weight formulation naturally benefits elevation angles offering the best visibility at any location within the radar detection domain.

\section{Radar data-processing strategies}

Section $4 \mathrm{a}$ will provide a presentation of the radar data-processing strategies implemented to assess the algorithms proposed in section 3. Afterward, section $4 \mathrm{~b}$ will detail the implementation conditions for the various strategies proposed.

\section{a. Description of the various strategies}

The strategies implemented include a nonadaptive processing strategy with the algorithm made operational in 2002 (OPER2002), two time-adaptive strategies (T-AD1 and T-AD2), and four space-time-adaptive 
TABLE 5. Summary of the main features inherent in the various radar processing strategies implemented.

\begin{tabular}{|c|c|c|c|c|c|c|c|}
\hline & \multirow{2}{*}{$\begin{array}{l}\text { Nonadaptive } \\
\text { strategy } \\
\text { OPER2002 }\end{array}$} & \multicolumn{2}{|c|}{$\begin{array}{l}\text { Time-adaptive } \\
\text { strategies }\end{array}$} & \multicolumn{4}{|c|}{ Space-time-adaptive strategies } \\
\hline & & T-AD1 & T-AD2 & ST-AD1 & ST-AD2 & ST-AD3 & ST-AD4 \\
\hline $\begin{array}{l}\text { Clutter } \\
\text { identification }\end{array}$ & $\begin{array}{l}\text { MAD analog } \\
\text { method }\end{array}$ & \multicolumn{2}{|c|}{$\begin{array}{l}\text { Method proposed } \\
\text { in section 3a }\end{array}$} & \multicolumn{4}{|c|}{ Method proposed in section $3 \mathrm{a}$} \\
\hline $\begin{array}{l}\text { Rain separation; } \\
\text { NVPR used }\end{array}$ & No & \multicolumn{2}{|c|}{$\begin{array}{l}\text { No rain separation; } \\
\text { global apparent } \\
\text { NVPR }\end{array}$} & \multicolumn{3}{|c|}{ Rain separation; inversion rain-typed NVPRs } & $\begin{array}{l}\text { Rain separation; } \\
\text { apparent rain-typed } \\
\text { NVPRs }\end{array}$ \\
\hline $\begin{array}{l}\text { Screening } \\
\text { correction }\end{array}$ & No & \multicolumn{2}{|c|}{ Yes } & \multicolumn{4}{|c|}{ Yes } \\
\hline $\begin{array}{c}\text { Compositing } \\
\text { procedure }\end{array}$ & $\begin{array}{l}\text { Pseudo } \\
\text { CAPPI }\end{array}$ & \multicolumn{2}{|c|}{$\begin{array}{l}\text { Method proposed } \\
\text { in section } 3 c\end{array}$} & \multicolumn{4}{|c|}{ Method proposed in section $3 \mathrm{c}$} \\
\hline $\begin{array}{l}Z-R \\
\quad \text { relationships }\end{array}$ & $\begin{array}{c}\text { Single: } Z= \\
200 R^{1.6}\end{array}$ & $\begin{array}{c}\text { Single: } Z= \\
200 R^{1.6}\end{array}$ & $\begin{array}{c}\text { Single: } Z= \\
300 R^{1.4}\end{array}$ & $\begin{array}{l}\text { Single: } Z \\
\quad=200 R^{1.6}\end{array}$ & $\begin{array}{c}\text { Single: } Z= \\
300 R^{1.4}\end{array}$ & $\begin{array}{l}\text { Double: For } \\
\text { nonconvective } \\
\text { pixels, } Z=200 R^{1.6} \\
\text { for convective } \\
\text { pixels, } Z=300 R^{1.4}\end{array}$ & $\begin{array}{l}\text { Double: For } \\
\text { nonconvective pixels, } \\
\begin{array}{l}Z=200 R^{1.6} \text {; for } \\
\text { convective pixels, } \\
Z=300 R^{1.4}\end{array}\end{array}$ \\
\hline
\end{tabular}

strategies (ST-AD1, ST-AD2, ST-AD3, and ST-AD4). All of these strategies share the following characteristics: 1) except for OPER2002, reflectivity correction factors are evaluated for each elevation angle used to account for screening effects and NVPR and the reflectivity at ground is estimated with Eq. (5), 2) the radar hydrological products (i.e., rain-rate fields) are established over $1-\mathrm{km}^{2}$ Cartesian meshes with a time resolution of $5 \mathrm{~min}$, and 3 ) no radar-rain gauge adjustment and/or external meteorological information is applied to constrain the radar processing algorithms. A summary of the primary features of these strategies is given in Table 5 to help to interpret the results in section 5 .

\section{1) EXAMPLE OF NONADAPTIVE PROCESSING STRATEGY: OPER2002}

An adaptive clutter identification method, based on pulse-to-pulse variability of the reflectivity, had already been implemented at the time by Météo-France. As opposed to the new method (section 3a), this procedure employed an electronic processing system, and the gradient criterion now used to process clutter edge effects more effectively was not introduced. Moreover, an empirical relationship was implemented (instead of the elimination and interpolation scheme) to "attenuate" cluttered reflectivity with respect to the pulse-to-pulse variability criterion. Screening and VPR corrections were not applied, and the compositing procedure to establish the 2D hydrological product from 3D volume data only made use of reflectivity measurements from the three low elevation angles (Table 2). A fixed rangedependent compositing strategy, termed pseudo CAPPI hereinafter, was preferred: the $1.8^{\circ} \mathrm{PPI}$ measurements were entered over the $0-35-\mathrm{km}$ range, the $1.2^{\circ} \mathrm{PPI}$ measurements were entered over the $35-75-\mathrm{km}$ range and the $0.8^{\circ}$ PPI measurements were entered for ranges exceeding $75 \mathrm{~km}$, regardless of the intervening relief. Last, the Marshall-Palmer relationship $\left(Z=200 R^{1.6}\right)$ was introduced for the reflectivity-rain-rate conversion.

\section{2) TIME-ADAPTIVE RADAR PROCESSING STRATEGIES}

Two variants (T-AD1 and T-AD2), similar to the radar processing strategies currently operational within the Swiss and French radar networks (Germann et al. 2006; Tabary 2007), were tested as part of this effort. They both display the following features. The clutter identification and correction technique is the one proposed in section 3a. A single apparent NVPR is evaluated from Eq. (3) every $5 \mathrm{~min}$ at close range $(60 \mathrm{~km})$ using a 1-h moving time window. Regarding rainfall estimation, the reflectivity is extrapolated at ground level with the method described in section 3c. A unique $Z-R$ relationship is added for the reflectivity-rain-rate conversion over the radar detection domain. Strategies T-AD1 and T-AD2 differ in the choice of $Z-R$ relationship. As previously mentioned, this paper is not intended to optimize the choice of $Z-R$ relationship. We have consequently considered two relations with broad operational experience [e.g., for the Next-Generation Weather Radar (NEXRAD) network] with $Z=200 R^{1.6}$ (T-AD1) for widespread rainfall and $Z=300 R^{1.4}$ (T-AD2) for convective rainfall.

\section{3) SPACE-TIME-ADAPTIVE STRATEGIES}

The rain separation algorithm is implemented for the space-time-adaptive strategies. For ST-AD1, 2, and 3, the rain-typed NVPRs are derived from the inversion 
method [section $3 b(2)]$. The three variants 1,2 , and 3 all differ in the choice of $Z-R$ relationship: ST-AD1 utilizes a single $Z-R$ relationship with $Z=200 R^{1.6}$, ST-AD2 inputs $Z=300 R^{1.4}$, and ST-AD3 makes simultaneous use of the two $Z-R$ relationships, with $Z=200 R^{1.6}$ for both the stratiform and undetermined pixels and $Z=$ $300 R^{1.4}$ for the convective pixels. For ST-AD4, we have reduced algorithm complexity: this strategy is similar to ST-AD3, except that the apparent NVPRs derived from Eq. (3) are considered instead of the inversion NVPRs.

Several other algorithm combinations could have been implemented as well. With the selection proposed above, we are able to focus on assessing the space-timeadaptive algorithms described in section 3 .

\section{b. Implementation of all processing strategies}

Several points relevant to implementation of the proposed radar processing strategies will be addressed below: 1) radar calibration stability verifications, 2) quantification of screening effects, and 3) analysis of the NVPRs obtained for all of the various rain events.

\section{1) RADAR CALIBRATION STABILITY VERIFICATIONS}

Radar signal stability is a necessary yet insufficient condition for radar QPE (Joss and Waldvogel 1990). An electronic radar calibration is automatically performed on a daily basis by Météo-France for a number of radar parameters (transmitted power, certain points on the receiver rating curve, etc.). In accordance with Rinehart (1978), Delrieu et al. (1995), and Andrieu et al. (1997), we verified radar stability using external targets provided by ground clutter. The stability verification region was defined with a reflectivity threshold of $45 \mathrm{dBZ}$, MAD values of less than $2 \mathrm{dBZ}$, and reflectivity values observed within a $10-50-\mathrm{km}$ radar range. This setup ensures strong reflections with little variation from pulse to pulse and avoids receiver saturation. The mean reference target values determined prior to the five selected rain events exhibit a variation range on the order of $0.5 \mathrm{~dB}$, which suggests a very high stability level of the transmitter-receiver system during the Bollène-2002 Experiment.

\section{2) SCREENING EFFECTS}

Screening effects were determined according to the geometrical procedure proposed by Delrieu et al. (1995), which employs a digitized terrain model with a space resolution of $50 \mathrm{~m}$ for this specific case. Radar wave propagation in the atmosphere is assumed to be described by the $4 / 3$ Earth-radius model (Doviak and Zrnic 1993). The geometrical calculation considers a Gaussian model for the normalized power gain function

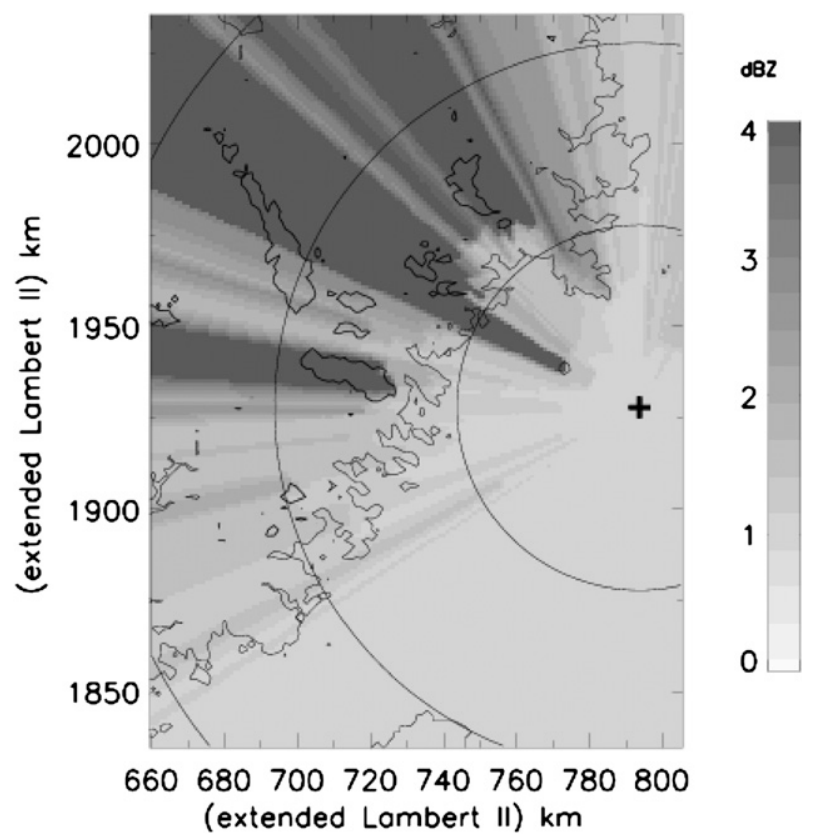

FIG. 9. Screening factors for the Bollène radar estimated using a digital terrain model for the $0.4^{\circ}$ elevation angle. Screening factors are expressed in reflectivity decibels to be added to the reflectivity value if screening is assumed to be the only source of beam-filling heterogeneity (e.g., a 3-dBZ correction factor for a half-screened beam).

truncated for an angle value equal to 2 times the 3 -dB beamwidth. This threshold is required to correctly represent clutter due to mountainous targets. The screening factors are expressed in terms of the correction factor $(\mathrm{dB})$ that should be added to reflectivity $(\mathrm{dBZ})$ if the screening effect was the only source of heterogeneity in the radar beam filling (e.g., a halfscreened beam would require a $3-\mathrm{dB}$ additive correction). Screening factors in the range from 2 to $10 \mathrm{~dB}$ are observed over most of the northeastern sector of the CVMHO window for the $0.4^{\circ}$ elevation angle (Fig. 9), and the maximum screening factor is $1.8 \mathrm{~dB}$ for the $1.2^{\circ}$ elevation angle. The higher elevation angles are devoid of screening effects.

\section{3) ANALYSIS OF NVPRS FOR VARIOUS RAIN EVENTS}

An example of the variability in inversion NVPRs identified for two events in the Bollène experiment is shown in Fig. 10. The NVPRs are estimated every 5 min using a 60-min moving time window. The vertical extension of the 8-9 September 2002 event (MCS) is noteworthy, in comparison with the 10-13 December 2002 event (shallow convection), for both the convective and stratiform regions. On average, the MCS convective NVPR displays a gradient of $-5 \mathrm{~dB} \mathrm{~km}^{-1}$ 

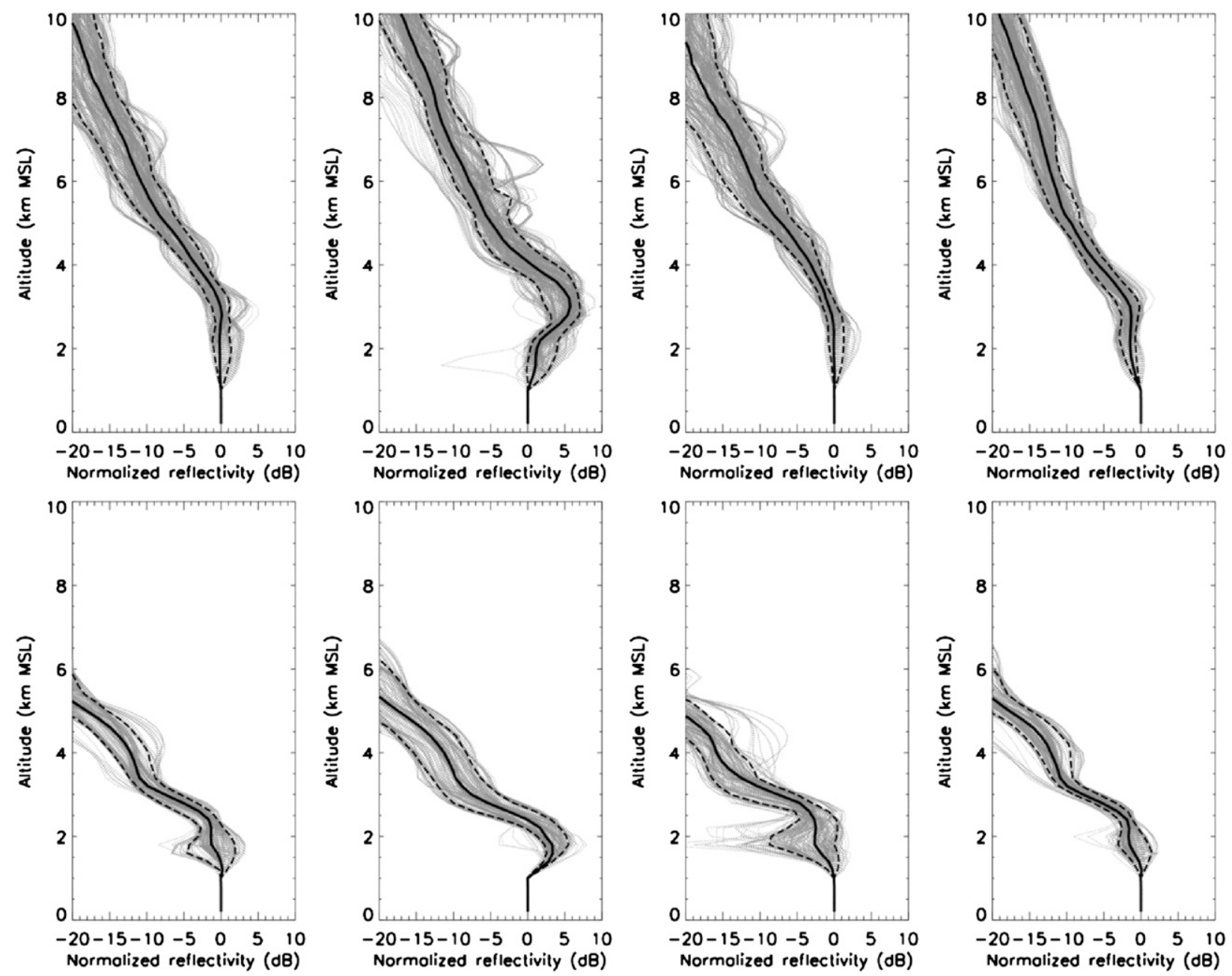

FIG. 10. Inversion NVPRs (gray curves) for the (top) 8-9 Sep 2002 and (bottom) 10-13 Dec 2002 cases for (left) global estimation without rain typing and estimation for the (second from left) stratiform, (third from left) convective, and (right) undetermined pixels. Distribution quantiles are displayed with both dotted (10\% and $90 \%$ quantiles) and solid (median) black lines.

between 3 and $4 \mathrm{~km} \mathrm{MSL}$ and $-3 \mathrm{~dB} \mathrm{~km}^{-1}$ above $4 \mathrm{~km}$ MSL. The stratiform NVPR revealed a brightband altitude of $3.2 \mathrm{~km}$ and a peak of about $5 \mathrm{~dB}$ as well as a gradient of $-2 \mathrm{~dB} \mathrm{~km}^{-1}$ above $4 \mathrm{~km}$ MSL. The NVPRs decrease much faster versus altitude for the 10-13 December case (e.g., with a gradient of approximately $-10 \mathrm{~dB} \mathrm{~km}^{-1}$ for the convective VPRs above $3 \mathrm{~km} \mathrm{MSL}$ ). The shapes of the convective and stratiform NVPRs are clearly distinct for each single rain event, and the global NVPR lies between the two. The identified brightband altitudes are consistent with the radio soundings available for the two events: the $0^{\circ} \mathrm{C}$ isotherm was positioned at an altitude of $3300 \mathrm{~m}$ MSL for the September case and between 1500 and $1900 \mathrm{~m}$ MSL for the December case. The NVPR estimated for the undetermined pixels is close to the global one; however, it frequently exhibits (see Fig. 10) a slight shift just above the reference level
(0-1 km MSL), with respect to a normalization problem: as range increases, fewer reflectivity measurements are available at the reference level. For this reason, we will be applying the global NVPR to correct the undetermined pixels.

Two other facts need to be mentioned herein. The spread of NVPR distributions is limited for a given rain event, which indicates that NVPR time variability remains relatively low. Furthermore, some erratic NVPRs are estimated when an insufficient quantity of information is available (e.g., for the convective NVPRs of the 10-13 December 2002 case in Fig. 10). In real-time operations, criteria will therefore be required to assess the robustness of a given NVPR. In this preliminary study, we have decided to consider NVPRs as not being robust when at least one point lies outside the $10 \%$ and $90 \%$ quantile intervals of the distributions shown in 
Fig. 10. In such cases, the corresponding median NVPR has been used instead.

\section{Assessment}

For an assessment of the various radar processing strategies, we relied upon the kriging estimates as reference rainfall for the $1-\mathrm{km}^{2}$ radar meshes containing a rain gauge (see section $2 \mathrm{~b}$ ). For the assessment criteria, we have used mean relative error $[\mathrm{MRE}=(\bar{R}-\bar{G}) / \bar{G}$, where $\bar{G}$ and $\bar{R}$ stand for rain gauge and radar mean rain amounts, respectively] for the bias assessment and the determination coefficient (square of the linear correlation coefficient) to evaluate scatter. The Nash coefficient $\left[N=1-\overline{(G-R)^{2}} / \overline{(G-\bar{G})^{2}}\right]$, classically used in hydrology to assess performance of a given estimator with respect to reference values, has also been considered. Recall that perfect agreement in terms of bias and scatter (i.e., all points lying on the 1:1 line) yields a Nash coefficient of 1 , whereas a value of less than 0 is obtained when estimator output is as poor as a simple average of the reference values.

\section{a. Global assessment}

Figure 11 presents examples, for two strategies (T-AD1 and ST-AD3), of radar-rain gauge scatterplots obtained by grouping data from all five rain events. The results displayed correspond to comparison points located within $100 \mathrm{~km}$ of the radar. Attention should first be focused on the scatterplot scales, with variation ranges of $0-140 \mathrm{~mm} \mathrm{~h}^{-1}$ and $0-700 \mathrm{~mm}$ for the hourly and event time steps, respectively. It is mentioned again that the radar estimates were obtained independent of the rain gauge measurements (i.e., no radar-rain gauge merging at any radar processing stage). Furthermore, the $Z-R$ relationships used were not optimized with respect to Mediterranean climatological values. The overall level of radar-rain gauge agreement shown in Fig. 11 is therefore high, especially at the event time scale with Nash coefficient values of 0.84 and 0.89 and determination coefficient values of 0.89 and 0.89 for the T-AD1 and ST-AD3 strategies, respectively. The MRE values of $-16.4 \%$ and $-7.4 \%$ indicate, however, a considerable underestimation by radar. As expected, the overall radar-rain gauge performance drops at the hourly time step, with Nash coefficients of 0.75 and 0.74 for the T-AD1 and ST-AD3 strategies, respectively. Scatter increases (determination coefficients of 0.76 and 0.74 ) and the bias is lower at the hourly time step, with MRE values of $-9.8 \%$ and $0 \%$ for T-AD1 and ST-AD3, respectively.

The criteria values obtained by the various radar processing strategies are presented in Fig. 12. The most striking result is that all tested strategies, with the exception of OPER2002, reveal very similar performance in terms of scatter while the bias criterion exhibits marked variations as a function of the specific processing strategy. To be more precise:

- The performance of OPER2002 was adversely affected by the residual ground clutter that accumulates over the event time scale and that leads to dramatic overestimations. The OPER2002 bias (MRE = $1.3 \%$ at the event time step) was small but for the wrong reasons, with the cluttered pixels compensating in some way for the radar rainfall underestimation.

- By implementing the new clutter processing strategy, which accounts for the global NVPR time series specific to each event and produces weighted average combinations of the corrected reflectivities vertically, the time-adaptive strategies (T-AD1 and T-AD2) offer clear progress with respect to OPER2002 in terms of both the determination coefficient and Nash coefficient. However, the MRE criterion becomes negative, indicating considerable underestimation on average by radar.

- For the choice of $Z-R$ relationship, a comparison between the Nash coefficients and MRE values for the T-AD1 and T-AD2 strategies reveals that use of the $Z=300 R^{1.4}$ relationship has a slightly beneficial impact relative to the $Z=200 R^{1.6}$ relationship. This trend is confirmed when incorporating the performance of the space-time-adaptive strategies ST-AD1 and ST-AD2.

- A comparison of criteria both for T-AD1 and ST-AD1 and for T-AD2 and ST-AD2 indicates that the "partial" regionalization (application of rain-typed NVPRs only) has no impact at the event time step and even exerts a slightly detrimental impact at the hourly time step in terms of scatter, whereas the MRE criterion is slightly improved.

- A comparison of ST-AD3 with both ST-AD1 and ST-AD2 suggests that the "full" regionalization (application of both rain-typed NVPRs and $Z-R$ relationships) yields a very large reduction in bias, whereas the scatter remains basically unchanged.

- In addition, we can note that use of the inversion approach (ST-AD3) for VPR estimation has a positive impact in terms of bias reduction with respect to use of the apparent NVPRs (ST-AD4).

It is interesting to interpret the MRE criterion in terms of a radar calibration error $\Delta Z(\mathrm{dBZ})$ that could be derived from the radar-rain gauge comparisons through $\Delta Z=10 b \log [1 /(1-\mathrm{MRE})]$. The $\Delta Z$ values (to be added to the measured reflectivity) obtained equal 

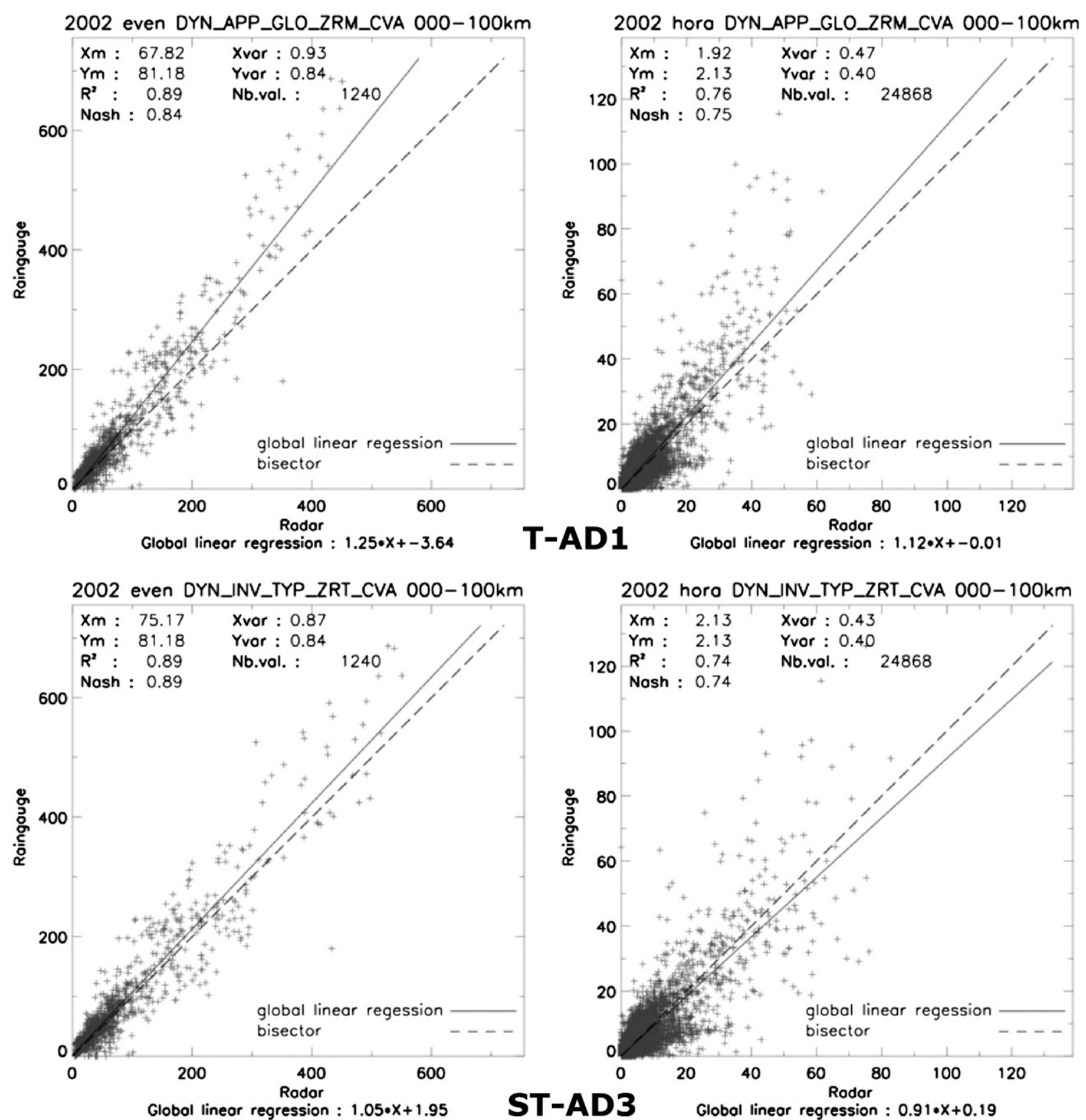

FIG. 11. Scatterplots of the radar-rain gauge comparison over the set of five rain events selected at the (left) event and (right) hourly time steps for the (top) T-AD1 and (bottom) ST-AD3 radar processing strategies.

approximately +1.2 and +0.7 for T-AD1 (and ST-AD1), +0.8 and +0.4 for T-AD2 (and ST-AD2), and +0.5 and 0 for ST-AD3, for the event and hourly time steps, respectively. These figures demonstrate: 1) a good absolute radar calibration quality of the Bollène-2002 dataset (slight underestimation between 0 and $+1.2 \mathrm{dBZ}$ ), and 2) the dependence of such radar calibration error estimates on both the $Z-R$ relationship (roughly
0.3-0.4 $\mathrm{dBZ}$ ) and the integration time step (about $0.4-0.5 \mathrm{dBZ}$ ). The fact that the radar data basically appear unbiased for the ST-AD3 strategy is especially satisfactory from the standpoint of both the calibration maintenance of the radar system and the radar data processing implemented. In the bottom panel of Fig. 12, the Nash coefficient allows drawing a synthesis of results obtained in terms of targeted bias and 


\section{Mean relative error $(\%)$}

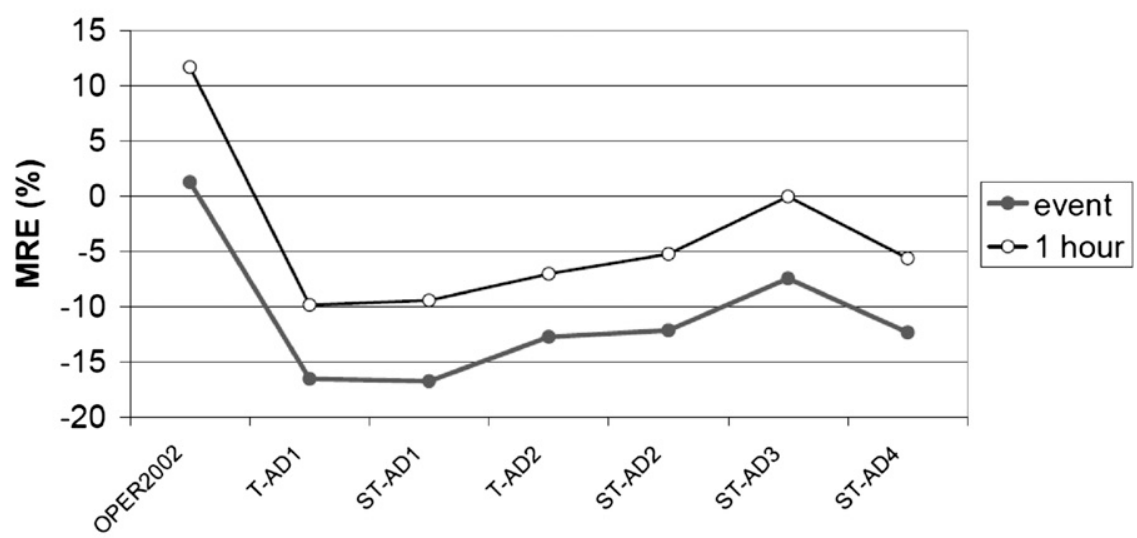

Determination coefficient

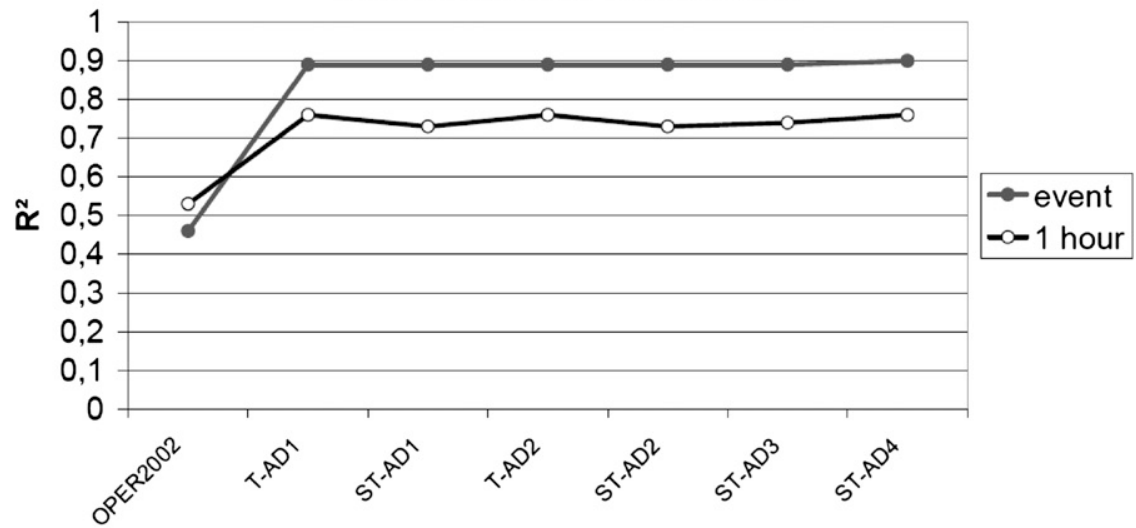

Nash coefficient

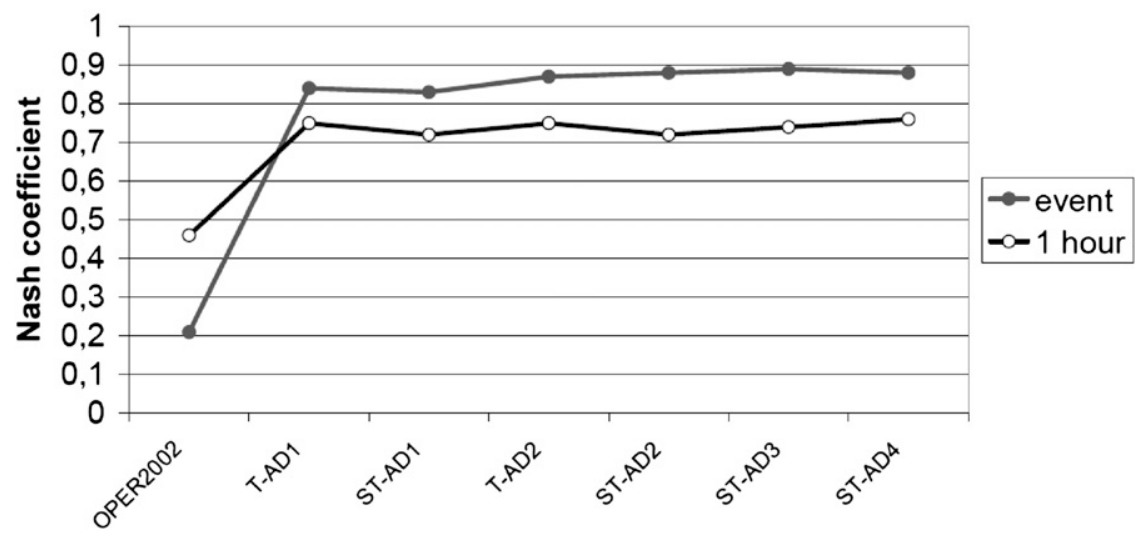

Radar processing strategy

FIG. 12. Evolution in assessment criteria at the event time step vs radar processing strategy for the $0-100-\mathrm{km}$ radar range interval: (top) mean relative error, (middle) determination coefficient, and (bottom) Nash coefficient.

scatter: according to this criterion, the ST-AD3 strategy is slightly better than the other approaches at the event time step, and no significant trend can be observed at the hourly time step.

\section{b. Detailed assessment}

Given that the 8-9 September 2002 rain event has a major influence on the criteria presented in the previous 

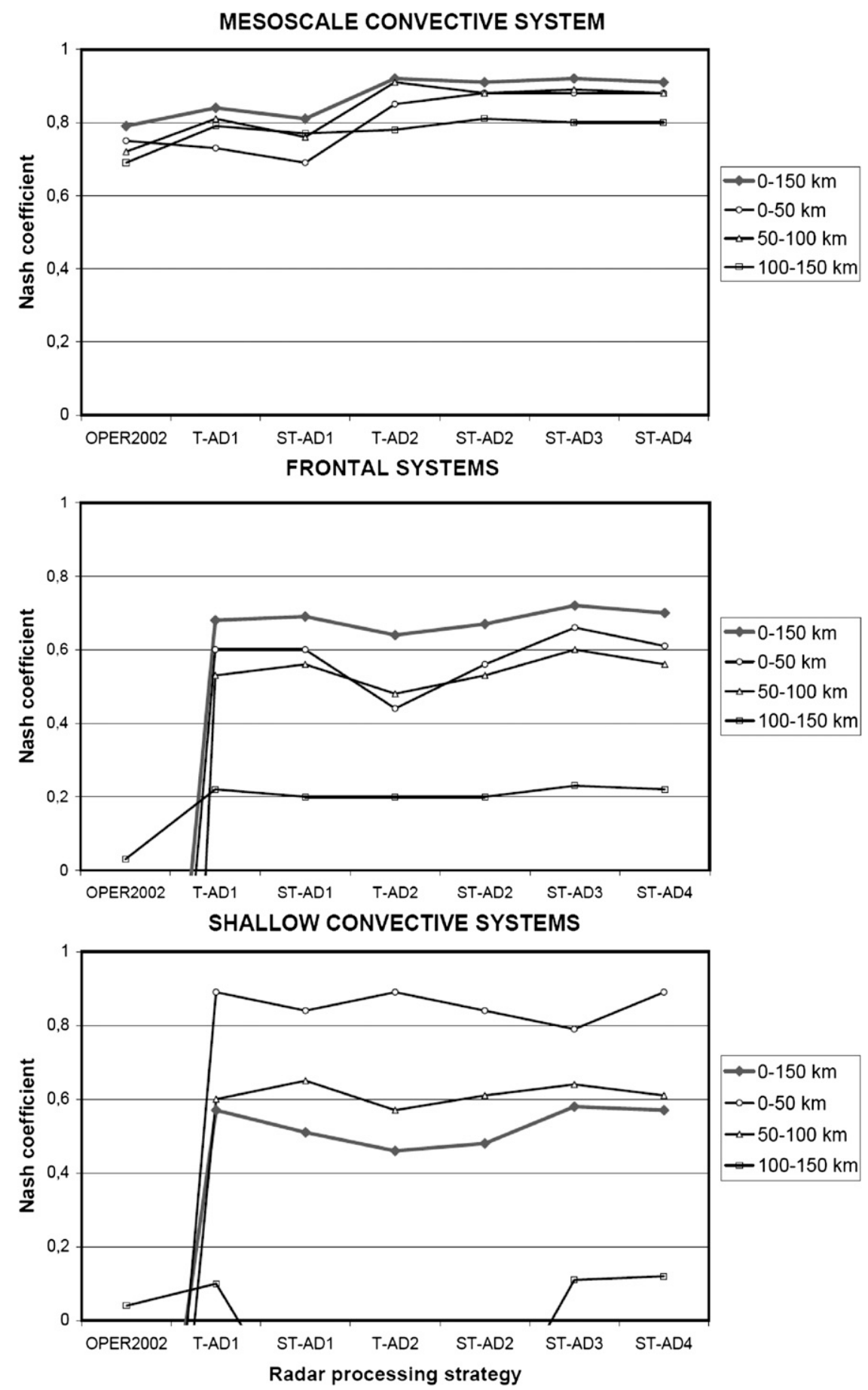

FIG. 13. Nash coefficient evolution at the event time step vs radar processing strategy for various radar range intervals and the three rain-event groups.

section, we found it useful to analyze results for the various events corresponding to diverse rainfall systems typical of a Mediterranean climate (Table 3). To limit the amount of material to be displayed, we grouped the events into the three following categories:
1) mesoscale convective system for $8-9$ September 2002 ,

2) frontal systems for 21 October and 21 November 2002 , and

3) shallow convective systems triggered by orography for 24 November and 10-13 December 2002. 
Figure 13 shows the evolution in Nash criterion calculated globally for the five rain events and the three event groups defined above for the event time step. Note that the scatter and bias criteria (not displayed for the sake of conciseness) exhibit the trends indicated in section 5a. An assessment of the spatial performance of the various strategies will be proposed as well. Four range intervals will be considered with the $0-150-\mathrm{km}$ range interval and partial range intervals of $0-50,50-100$, and $100-150 \mathrm{~km}$. The corresponding rain gauge networks (Fig. 2) contain 356, 74, 175, and 107 gauges, respectively.

The most striking result from Fig. 13 is that the Nash criteria are greatly improved for the MCS case (approximately 0.9 ) relative to events from the other two groups $(0.5-0.7)$; this finding is related to the huge vertical extension of the MCS event, which makes for much easier observation by radar. Moreover, this event has mainly affected regions in the $100-\mathrm{km}$ range with good radar visibility (i.e., the Gard plains rather than the Cévennes Mountain ridge). Also note that the Nash criteria calculated globally are better than those calculated for each class of distances for two of the three groups (MCS and frontal systems). Such a result might come as a surprise. It is simply related to the spatial variation of rain fields: an extended spatial domain may lead to increased rainfall variance, which in turn can impact the Nash criterion in the manner observed. As a complement to Fig. 13, Fig. 3 displays the rain gauge and radar maps at the event time step for a single event from each group. The comments that follow below can then be put forward for the three groups of rain events.

For the 8-9 September 2002 case, the factor with the greatest impact is the choice of convective $Z-R$ relationship, with a clear advantage for the $Z=300 R^{1.4}$ relationship. The rain separation and typed VPR correction do not provide appreciable improvement in the Nash criterion, which is consistent with the structure of the event (characterized by clusters of very intense convective cells that remain nearly stationary over the region). The stratiform part of the system (Figs. 4 and 5) generated a much smaller contribution in terms of rainfall; the high altitude of the bright band $(3.2 \mathrm{~km})$ also explains the limited influence of the stratiform VPR corrections since several elevation angle measurements were available below the bright band over a large portion of the affected region. The Nash criterion is very similar for the $0-50-$ and $50-100-\mathrm{km}$ range intervals: it decreases slightly for ranges greater than $100 \mathrm{~km}$, where the event was actually much less intense.

For the rain events associated with cold front systems (e.g., 21 November 2002; see Fig. 3), radar performance is very good; once again, it is similar for the $0-50$ - and 50-100-km range intervals and drops very much for greater ranges because of the limited vertical extension of the rainfall as well as the subsequent radar observation problem. Of interest is that application of the $Z=$ $300 R^{1.4}$ relationship has a detrimental impact as compared with the $Z=200 R^{1.6}$ relationship, which suggests the benefit of distinguishing frontal and deep convection through the use of specific $Z-R$ relationships. In addition, this offers the most convincing case for focusing on space-time-adaptive processing in this study, given the slight superioriy for ST-AD3 over all of the strategies considered, especially within the $0-50-\mathrm{km}$ range, although the $Z=300 R^{1.4}$ relationship is not in fact appropriate.

For rain events characterized by shallow convection and triggered by the orography, radar performance is good in the $0-50-\mathrm{km}$ range interval, greatly declines in the $50-100-\mathrm{km}$ range interval, and is very poor over longer ranges. Maps of the 10-13 December 2002 case (Fig. 3) confirm the estimation problem encountered in the southern part of the CVMHO window for this specific event. Once again, this is related to the low vertical extension of such rainfall systems (Fig. 10) and to the fact that they mostly affect the mountainous part of the CVMHO window with possible residual clutter impact. The detrimental impact of the $Z=300 R^{1.4}$ relationship is confirmed in this particular case. It can also be noticed that ST-AD3 fails close to the radar site while it works very well at longer ranges; on the other hand, an opposite trend is observed for ST-AD4, which may indicate that we are reaching certain validity limitations of the rain separation and VPR estimation methods for such shallow rain types.

\section{Summary and conclusions}

The Bollène-2002 Experiment has been intended to develop the use of a radar volume-scanning strategy for radar rainfall estimations in the mountainous regions of France. Along with the operational developments implemented by Météo France (Tabary 2007; Tabary et al. 2007), a developmental radar QPE processing system, called Traitements Régionalisés et Adaptatifs de Données radar pour l'Hydrologie (Regionalized and Adaptive Radar Data Processing for Hydrological Applications, or TRADHy), has been built at the LTHE Laboratory and several algorithms were developed during the study presented here. First, a clutter identification technique based on the pulse-to-pulse variability of reflectivity was proposed for this noncoherent radar. The clutter problem is particularly critical here, both because of the choice of working wavelength $(10 \mathrm{~cm})$ and because of the strong clutter contamination 
resulting from the mountainous environment and presence of considerable infrastructure in the Rhone Valley. Second, the issue of an automatic separation of rain types within the radar detection domain was addressed. The rain separation algorithms proposed by Steiner et al. (1995) and Sánchez-Diezma et al. (2000) were implemented-slightly adapted and synergized with a decision tree. Two methods for estimating VPR were then considered: an estimation of the apparent normalized VPR function, as estimated directly from measured reflectivities at close range, and an adaptation of the inversion technique developed by Andrieu and Creutin (1995) to the case of time-varying geographical regions. The concept of coupling the rain partition and VPR identification has also been proposed. Implementation of the rain-typing algorithms has provided an initial rain partition valid over close ranges (typically $60-80 \mathrm{~km}$ ). This preliminary partition was then used to identify the convective and stratiform NVPRs. As a subsequent step, the identified NVPRs were applied to improve rain typing at longer ranges through comparison with the local VPRs using a similarity criterion. Last, a method was proposed for calculating reflectivity at the ground level from reflectivities measured aloft. Correction factors that account for screening and VPR effects could be established for measurements at each elevation angle. A weighted average of the corrected reflectivity measurements available has also been implemented, with the weights being dependent upon the correction factors.

Several radar processing strategies (Table 5) were defined to assess new algorithm performance with respect to reference rainfall data derived from a careful analysis of the CVMHO rain gauge datasets. Assessment criteria for five intense and long-lasting Mediterranean rain events proved that precise quantitative precipitation estimates could be obtained from radar data alone within a range of $100 \mathrm{~km}$ from the radar by using well-sited, well-maintained radar systems and sophisticated, physically based data-processing systems. Performing accurate electronic calibration along with verifying stability, determining radar detection domain, eliminating clutter, and capturing the vertical structure(s) of reflectivity for the target event constitute the basic requisite ingredients. Radar performance was shown to depend on the type of the rain systems. Better results were obtained for deep convective events (Nash coefficients of about 0.90 for point radar-rain gauge comparisons at the event time step) in comparison with shallow convective and frontal rain systems (Nash coefficients of approximately $0.5-0.7$ ). This finding stems from the improved radar observation conditions for the former events. As opposed to time-adaptive strategies, the space-time-adaptive strategy produced a very significant reduction in radar-rain gauge bias, whereas the scatter remained basically unchanged. Because the $Z-R$ relationships were not optimized in this study, the result was attributed to improved processing of spatial variations of the vertical profile of reflectivity.

Some specific comments are listed below regarding the various TRADHy algorithms as well as anticipated future work. The new clutter processing algorithm functions satisfactorily; this result was difficult to achieve because of the strong contamination of the S-band radar signal within the considered context. Although Doppler and polarimetric radar systems undoubtedly offer enhanced capabilities for eliminating clutter and artifacts, the pulse-to-pulse variability of reflectivity proved to be an interesting working variable. Adding a gradient criterion to extend clutter detection at the edge of cluttered regions made it possible to remove residual clutter, which did have a very detrimental quantitative impact when accumulated over long periods of time. A technical memorandum is available from the authors for an in-depth documentation of the clutter identification algorithm. The Bollène low-elevation angles, however, are affected by clutter over large areas, which likely limits the radar QPE performance obtained in this study. Following this work, an increase in the number of low-elevation PPIs was proposed and implemented for the Bollène radar, with five PPIs at $0.8^{\circ}, 1.2^{\circ}, 1.8^{\circ}, 2.4^{\circ}$, and $3.6^{\circ}$ performed every $5 \mathrm{~min}$. These have been complemented by three upper-elevation PPIs alternating every $5 \mathrm{~min}$.

The rain separation algorithm behaved well; however, radar sampling properties inherently reduce performance over longer ranges. A valid practical range limit could be estimated at $80-100 \mathrm{~km}$. Although effective in principle, the concept proposed herein for a coupled identification of rain types and NVPRs still needs to be strengthened. Generalizing the algorithm to the pair of S-band radars at Bollène and Nîmes offers the most promising prospect for dramatically increasing the information available vertically for each individual pixel.

The assessment results indicate the positive impact from applying the inversion NVPRs (ST-AD3), in comparison with the apparent NVPRs (ST-AD4), in terms of bias reduction. This finding is attributed to both a reduction in radar sampling effects provided by the inversion method and the fact that this method samples VPR variability over a larger and more representative region (the CVMHO window within a radar range of $120 \mathrm{~km}$ here, vs an area extending over a $60-\mathrm{km}$ range for the apparent VPR estimation). As mentioned in section $3 \mathrm{~b}$, adaptation of the inversion technique developed by Andrieu and Creutin (1995) has proven 
difficult within the current context given the need to aggregate data over a period as long as $1 \mathrm{~h}$ and with having to implement a ratio data-censoring approach to reach a satisfactory level of robustness. A new method for identifying a reduced number of physically based parameters to describe NVPR evolution as a function of altitude is also in the development stages.

Further research still needs to be devoted to the crucial link between measurable radar parameters in a vertical atmospheric column and rainfall at ground level. We have employed $Z-R$ relationships from the literature with some success here. It is interesting that the convective $Z-R$ relationship introduced was found to be well suited to the deep convection case of 8-9 September 2002 and to be not appropriate for the frontal and shallow convective cases. Chapon et al. (2008) first addressed the topic of space-time variability of the $Z-R$ relationship in the Cévennes region by use of DSD measurements at ground level. Several years of DSD data are now available for an in-depth characterization of $Z-R$ relationships specific to Mediterranean climatological values.

Research efforts will be intensified within the Cévennes-Vivarais region over the coming years through an ambitious experimental program currently being set up by the CVMHO teams as part of the Hydrological Cycle in the Mediterranean Experiment (HyMeX; http:// www.cnrm.meteo.fr/hymex/). Implementation of Doppler and polarimetric capabilities for the operational radar network, deployment of additional research radar systems and disdrometer networks, combined with the use of nonhydrostatic, high-resolution meteorological models, should contribute to improving the observation, modeling, and forecasting of high-rainfall Mediterranean storms.

Acknowledgments. The authors thank J. Parent du Châtelet and P. Tabary (DSO/Météo-France), who made it possible to use operational radar for research purposes. We also thank L. Périer and K. Dokhac (DSO/ Météo France), who developed the new CASTOR2 radar processing system for the French ARAMIS radar network and very efficiently implemented this system during the Bollène-2002 Experiment. Fruitful discussions and software exchanges were held with D. Sempere-Torres, R. Sánchez-Diezma, and the GRAHI group at the Polytechnical University of Catalunya, Spain. This study was funded by a research agreement between France's CNRS Institute and Météo-France, through the integrated FP6 FLOODSITE project of the European Community (GOCE-CT-2004-505420) and the Cluster Environnement of the Rhone-Alps Region.

\section{REFERENCES}

Andrieu, H., and J. D. Creutin, 1995: Identification of vertical profiles of reflectivity for hydrological applications using an inverse method. Part I: Formulation. J. Appl. Meteor., 34, 225-239.

_, G. Delrieu, and J. D. Creutin, 1995: Identification of vertical profiles of reflectivities for hydrological applications using an inverse method. Part II: Sensitivity analysis and case study. J. Appl. Meteor., 34, 240-259.

— J. D. Creutin, G. Delrieu, and D. Faure, 1997: Use of a weather radar for the hydrology of a mountainous area. Part I: Radar measurement interpretation. J. Hydrol., 193, 1-25.

Chapon, B., 2006: Etude des pluies intenses en région CévennesVivarais à l'aide du radar météorologique-Régionalisation des traitements radar et analyse granulométrique des pluies au sol (Radar observation of intense Mediterranean precipitation: Radar data processing regionalization and analysis of drop size distribution at ground). Ph.D. thesis, University Joseph Fourier, Grenoble, France, 189 pp.

- G. Delrieu, M. Gosset, and B. Boudevillain, 2008: Variability of rain drop size distribution and its effet on the $Z-R$ relationship: A case study for intense Mediterranean rainfall. Atmos. Res., 87, 52-65.

Ciach, J. G., and W. F. Krajewski, 1999: On the estimation of radar rainfall error variance. Adv. Water Resour., 22, 585-595.

Creutin, J. D., and C. Obled, 1982: Objective analysis and mapping techniques for rainfall fields: An objective comparison. Water Resour. Res., 18, 413-431.

— G. Delrieu, and T. Lebel, 1988: Rain measurement by raingage-radar combination: A geostatistical approach. J. Atmos. Oceanic Technol., 5, 102-115.

Delrieu, G., A. Bellon, and J. D. Creutin, 1988: Estimation de lames d'eau spatiales à l'aide de données de pluviomètres de radar météorologique (Comparative study of areal rainfall estimation methods using rain gauge and radar data). J. Hydrol., 98, 315-344.

_ J. D. Creutin, and H. Andrieu, 1995: Simulation of X-band weather radar mountain returns using a digitized terrain model. J. Atmos. Oceanic Technol., 12, 1038-1049.

_ , and Coauthors, 2005: The catastrophic flash-flood event of 8-9 September 2002 in the Gard region, France: A first case study for the Cévennes-Vivarais Mediterranean hydrometeorological Observatory. J. Hydrometeor., 6, 34-52.

Dinku, T., E. N. Anagnostou, and M. Borga, 2002: Improving radar-based estimation of rainfall over complex terrain. J. Appl. Meteor., 41, 1163-1178.

Doviak, R. J., and D. S. Zrnic, 1993: Doppler Radar and Weather Observations. Academic Press, 562 pp.

Germann, U., and J. Joss, 2002: Mesobeta profiles to extrapolate radar precipitation measurements above the Alps to the ground level. J. Appl. Meteor., 41, 542-557.

_, G. Galli, M. Boscacci, and M. Bolliger, 2006: Radar precipitation measurement in a mountainous region. Quart. J. Roy. Meteor. Soc., 132, 1669-1692.

Habib, E., J. G. Ciach, and W. F. Krajewski, 2004: A method for filtering out raingauge representativeness errors from the verification distributions of radar and raingauge rainfall. $A d v$. Water Resour., 27, 967-980.

Jacq, V., 1994: Inventaire des situations à précipitations diluviennes sur les régions Languedoc-Roussillon, PACA et Corse, période 1958-1994 (Inventory of extreme precipitation events in the Languedoc-Roussillon, Provence Côte d'Azur 
and Corse regions in the period 1958-1994). Phénomènes Remarquables, No. 3, Météo France, 190 pp.

Joss, J., and A. Waldvogel, 1990: Precipitation measurement and hydrology. Radar in Meteorology: Battan Memorial and 40th Anniversary Radar Meteorology Conference, D. Atlas and L. J. Battan, Eds., Amer. Meteor. Soc., 577-606.

Kirstetter, P.-E., 2008: Estimation quantitative des précipitations par radar météorologique: inférence de la structure verticale des pluies et modélisation des erreurs radar-pluviomètres (Radar quantitative precipitation estimation: inference of the vertical profile of reflectivity, radar-rain gauge error model). Ph.D. thesis, University Joseph Fourier, Grenoble, France, 210 pp.

Lebel, T., G. Bastin, C. Obled, and J. D. Creutin, 1987: On the accuracy of areal rainfall estimation: A case study. Water Resour. Res., 23, 2133-2134.

Pellarin, T., G. Delrieu, G. M. Saulnier, H. Andrieu, B. Vignal, and J. D. Creutin, 2002: Hydrologic visibility of weather radars operating in mountainous regions: Case study for the Ardèche catchment (France). J. Hydrometeor., 3, 539-555.

Rinehart, R. E., 1978: On the use of ground return targets for radar reflectivity factor calibration checks. J. Appl. Meteor., 17, 1342-1350.

Rivrain, J. C., 1998: Les épisodes orageux à précipitations extrêmes dans les régions méditerranéennes du sud de la France (Extreme storm-floods in the Mediterranean region of southern France). Phénomènes Remarquables, No. 4, Météo-France, 93 pp.

Sánchez-Diezma, R., I. Zawadzki, and D. Sempere-Torres, 2000: Identification of the bright band through the analysis of volumetric radar data. J. Geophys. Res., 105, 2225-2236.
Steiner, M., R. A. Houze Jr., and S. E. Yuter, 1995: Climatological characterization of three-dimensional storm structure from operational radar and rain gauge data. J. Appl. Meteor., 34, 1978-2007.

Tabary, P., 2007: The new French operational radar rainfall product. Part I: Methodology. Wea. Forecasting, 22, 393-408.

— J. Jesplats, K. Do Khac, F. Eideliman, C. Guégen, and J.-C. Heinrich, 2007: The new French operational radar rainfall product. Part II: Validation. Wea. Forecasting, 22, 409-427.

Vignal, B., and W. F. Krajewski, 2001: Large-sample evaluation of two methods to correct range-dependent error for WSR-88D rainfall estimates. J. Hydrometeor., 2, 490-504.

- , H. Andrieu, and J. D. Creutin, 1999: Identification of vertical profiles of reflectivity from volume scan radar data. J. Appl. Meteor., 38, 1214-1228.

_ G. Galli, J. Joss, and U. Germann, 2000: Three methods to determine profiles of reflectivity from volumetric radar data to correct precipitation estimates. J. Appl. Meteor., 39, 17151726.

Westrick, K. J., C. F. Mass, and B. A. Colle, 1999: The limitations of the WSR-88D radar network for quantitative precipitation measurement over the coastal western United States. Bull. Amer. Meteor. Soc., 80, 2289-2298.

Wilson, J. W., and E. A. Brandes, 1979: Radar measurement of rainfall-A summary. Bull. Amer. Meteor. Soc., 60, 1048-1058.

Young, B. C., B. R. Nelson, A. A. Bradley, J. A. Smith, C. D. Peters-Lidard, A. Kruger, and M. R. Baeck, 1999: An evaluation of NEXRAD precipitation estimates in complex terrain. J. Geophys. Res., 104, 19 691-19 704. 